\title{
Energy-ecological Efficiency of Dual-Fuel Serie Plug- in Hybrid Electric Vehicle Considering WTW Emissions
}

\section{Laene Oliveira Soares}

CEFET/RJ: Centro Federal de Educacao Tecnologica Celso Suckow da Fonseca https://orcid.org/00000001-8305-2831

\section{Danielle Rodrigues de Moraes}

CEFET/RJ: Centro Federal de Educacao Tecnologica Celso Suckow da Fonseca

Luis Hernández-Callejo

Universidad de Valladolid

Ronney Arismel Mancebo Boloy ( $\nabla$ ronney.boloy@cefet-rj.br)

CEFET/RJ: Centro Federal de Educacao Tecnologica Celso Suckow da Fonseca https://orcid.org/00000002-4774-8310

\section{Research Article}

Keywords: Bioethanol, Biogas, Dual-fuel, Energy-ecological efficiency, Series PHEV, Well-to-wheel emissions

Posted Date: November 9th, 2021

DOI: https://doi.org/10.21203/rs.3.rs-1040457/v1

License: (9) This work is licensed under a Creative Commons Attribution 4.0 International License. Read Full License 


\title{
Energy-ecological Efficiency of Dual-Fuel Serie Plug-in Hybrid Electric Vehicle Considering WTW Emissions
}

\author{
Laene Oliveira Soares ${ }^{1,2}$ [0000-0001-8305-2831], Danielle Rodrigues de Moraes ${ }^{1,2}$ [0000-0001-8259-7020], Luis \\ Hernández-Callejo ${ }^{3}$ [0000-0002-8822-2948], Ronney Arismel Mancebo Boloy 1,2 [0000-0002-4774-8310] \\ ${ }^{1}$ Federal Centre of Technological Education Celso Suckow da Fonseca (CEFET), 20271-204 Rio de Janeiro, Brazil \\ ${ }^{2}$ Group of Entrepreneurship, Energy, Environment and Technology - GEEMAT \\ ${ }^{3}$ Department of Agricultural Engineering and Forestry, University of Valladolid, Campus Universitario Duques de \\ Soria, 42004 Soria, Spain \\ Corresponding author: ronney.boloy@cefet-rj.br
}

\begin{abstract}
This paper discussed the possibility of replacing the series plug-in hybrid electric vehicle using the single-fuel sparkignition engine (SFSIE) fuelled with gasoline A and Brazilian gasoline by the series plug-in hybrid electric vehicle fuelled with 50\% bioethanol and 50\% biogas in dual-fuel mode. The simulation of bioethanol, biogas and gasoline A combustion were carried out through GASEQ software to calculate the energy-ecological efficiency of the SFSIE and the dual-fuel spark ignition engine (DFSIE). The well-to-pump (WTP) emissions of the sugarcane bioethanol and biogas production pathway were evaluated through GREET software. The tank-to-wheel (TTW) emissions were determined to each series PHEV operating modes. Thus, the well-to-wheel emissions were calculated through the sum of the WTP, TTW and electricity mix emissions. The results showed that the energy-ecological efficiency for the DFSIE was $10.7 \%$ and $24.1 \%$ higher than that found for SFSIE fuelled with gasoline and Brazilian gasoline, respectively. The losses during the biogas production aggravate linearly the WTP emissions, and consequently the WTW emissions of the series PHEV. Besides that, the DFSIE presented 15.5\% and 12.8 less TTW emissions than the SFSIE fuelled with gasoline A and Brazilian gasoline, respectively. Comparing to the emission standards, the DFSIE presented TTW emissions 30.5\% higher than the EU emission standard by 2021. Although the DFSIE does not meet none of the emission standards, this engine mode can be an alternative to at least reduce the tailpipe emissions.
\end{abstract}

Keywords. Bioethanol; Biogas; Dual-fuel; Energy-ecological efficiency; Series PHEV; Well-to-wheel emissions.

\section{Introduction}

The biofuel is a sustainable option to replace the fossil fuel and reduce the global warming, caused by the greenhouse gas (GHG) emissions. Looking for an alternative to replace petroleum derived fuel, in Brazil, the Proálcool Program encourages the production of alcohol from sugarcane to being used to feed lightduty vehicles with flex spark-ignition engines. Brazil presents a relevant potential to produce biofuels, including taking advantage of the conversion of many organic wastes generated in the agroindustry. Besides that, Brazil has a mainly renewable electrical matrix, which $64.9 \%$ of the electricity generated comes from hydroelectric plants (EPE, 2020a). In 2019, the renewable sources including hydraulic, wind power, solar, sugarcane sources and biodiesel were responsible for $46.1 \%$ of the internal energy supply in Brazil (EPE, 2020a). The energy consumption of the transport sector increased in $3.3 \%$ in 2019, due to the use of biofuels, totalizing 25\%. However, the most used fuels were gasoline and diesel oil, which presented consumption of $25.3 \%$ and $41.9 \%$, respectively. Despite the biofuel consumption in Brazil is low compared to the fossil fuel consumption, Brazil is ahead of other member countries of the Organization for Economic Cooperation and Development (OECD), which presented 5\% use of renewable fuels in the transport sector in 2017 (EPE, 2020a). 
The electric vehicles (EV) are also an alternative to decrease the negative environmental effects caused by the fuel consumption. The plug-in hybrid electric vehicle (PHEV) is a type of EV that can be an alternative to reduce the GHG, once it can operate using an electric motor powered by the lithium-ion (Liion) battery or by the internal combustion engine (ICE). However, the components of the different types of $\mathrm{EV}$, in this case the PHEV, have advantages and disadvantages. The Li-ion battery presents advantages such as higher power and energy densities, and longer battery life than the other battery types. This battery type is selected because of its low self-discharge rate, which means the amount of charge lost when the battery is not used, and the absence of the memory effect, phenomenon that occurs in older batteries compound by $\mathrm{NiCd}$, basically, making them to acquire a charge capacity less and less, when a proper care in recharging is not carried out. But the disadvantage is that the Li-ion battery its cost is relatively higher than the other battery types. However, the manufacturing cost of the these batteries tends to decrease due to several factors, i.e., mass production, and its cost reduction will reinforce the importance of the renewable energy as an alternative to fossil fuels that aggravates the negative impacts to the environment and human health [2]. On the other hand, the ICE operates with fossil fuel or biofuel and can be classified as Otto cycle (spark-ignition), in which the fuel-air mixture is injected in the chamber and the combustion is made by the spark valve, or Diesel cycle (compression-ignition), which the ignition is caused when the fuel is sprayed in the chamber after the air is compressed. Although, focusing on decrease the GHG emissions caused by the PHEV, two point needs to be considered: first, the electricity that power the electric system have to be renewable, but it depends on the electricity source prevalent in each region; second, the ICE needs to be fuelled with biofuels, such as bioethanol and biogas once they cause lower negative effects than the fossil fuels, or adapting the ICE to operations in dual-fuel mode. The dual-fuel mode is a technology projected to burn two fuels at the same time. In this mode, an ICE (Otto or Diesel) is adapted to inject a gaseous fuel with air through the port injection, and a liquid fuel through a valve inside the chamber. This can reduce the environmental impact caused by the tailpipe emissions, once a percentage of more pollutant fuel can be replaced with a percentage of a less pollutant fuel. To make the use of the PHEV in dual-fuel mode viable, the TTW emissions of the engine must be low when compared to the tailpipe emissions standards recently provided by the European community $\left(95 \mathrm{gCO}_{2} / \mathrm{km}\right.$ by 2021 and $59 \mathrm{gCO}_{2} / \mathrm{km}$ by $\left.2030-\mathrm{IEA}\right)$ and by the United States $\left(89 \mathrm{gCO}_{2} / \mathrm{km}\right.$ by $\left.2024-\mathrm{EPA}\right)$.

In this study, the series PHEV Chevrolet Volt will be analysed. In general, the series PHEV presents differentiated operating modes, depending on the battery state of charge and driver's requests. The main modes are charge-sustaining (CS) mode; charge-depleting (CD) mode; EV mode and ICE mode [3]. In the CS mode, the ICE is the main power source, and the battery state of charge is controlled to stay within a limit between $30 \%$ and $40 \%$, depending on the battery type and the vehicle, to avoid any damage on the battery and decreasing of its number of recharge cycles. On the other hand, in CD mode, the battery is the main power source, and its state of charge is controlled to decrease during the operation of the vehicle. In this mode, the battery needs the power supplied by the ICE to meet the driver's requests, and the battery loss is greater, which can reduce its lifetime. In EV mode, the series PHEV operates as a battery electric vehicle (BEV), being powered exclusively by the battery. Finally, in ICE mode, the series PHEV operates as an internal combustion engine vehicle (ICEV), consuming fuel to generate power [3].

The grid-to-vehicle $(\mathrm{G} 2 \mathrm{~V})$ power and the possibility of bidirectional power through vehicle-to-grid (V2G) was investigated, i.e., to eventual residential supply. Mumtaz et al. (2017) developed a study about energy management and control system of charging station for PHEV, considering among other cases G2V and V2G. Hu et al. (2017) analysed the V2G interaction and its potential impact on the PHEV economy, and concluded that the battery aging cost induced by the $\mathrm{V} 2 \mathrm{G}$ outweighs the $\mathrm{V} 2 \mathrm{G}$-added revenue, requiring subsides from the grid to counterbalance this cost. Besides that, the use of algorithm construction methods has been studied by several articles for solving computational problems of combinatorial optimization such as dynamic programming. Wang and Liang (2017) applied the dynamic programming to formulate the 
energy management for PHEV via bidirectional V2G, aiming to minimize the daily energy cost. Zhang et al. (2017) conducted a study about power management in a PHEV using dynamic programming to optimize the control strategy in the model predictive control. The studies was also directed to the use of Li-ion battery in PHEV [2, 8], its degradation and its influence on fuel consumption [9].

To evaluate or compare the environmental impact caused by the PHEV and other EV types, and ICEV, the GHG emissions were analysed. De Souza et al. (2018) investigated the characteristics of PHEV, ICEV and BEV to analyse their environmental performance. According to the results, the PHEV and the ICEV presented similar environmental impact since they use ethanol or gasoline as fuel. Otherwise, the PHEV and the BEV presented higher results for human toxicity potential, because of the impact of the Li-ion battery production, but PHEV shows better results than BEV because of the lower weight of the battery [10]. Also, the GHG emissions depend on the electricity grid mix and of the vehicle usage [11].

Some studies related to life cycle assessment of the PHEV were published. De Souza et al. (2018) carried out a life cycle assessment to assess the well-to-wheel (WTW) for ICEV, PHEV and EV. The authors considered the ICEV with ICE powered by E25 gasoline, mixture of ethanol and gasoline (flex fuel vehicles), and ethanol, the PHEV with the ICE powered by gasoline, and the pure EV powered by electricity. The results showed that the ICEV fuelled with gasoline and in flex-mode presented the highest global environment impacts and suggested to analyse the impact categories isolated. Chen et al. (2018) investigated the life cycle $\mathrm{CO}_{2}$ emissions of the PHEV and the $\mathrm{BEV}$, through their performance and energy consumption over a four-month period and concluded that when the vehicles were in high speed or high acceleration conditions, the distance-normalized life cycle $\mathrm{CO}_{2}$ emissions of PHEV and BEV were higher then ICEV fuelled with gasoline. In the studies found, none analysed the life cycle assessment of the biogas and bioetanol from sugarcane through a detailed simulation on GREET software, considering the losses during the production process and its Well-to-Pump emissions.

In the case of dual-fuel mode, studies were directed to analyse its characteristics applied in ICEV with Otto cycle or Diesel cycle. Niu et al. (2016) studied the use of gasoline enriched with hydrogen in the Otto cycle, and concluded that flame developing duration and combustion duration were reduced with the addition of hydrogen in gasoline. Chen et al. (2019) evaluated the Otto cycle fuelled with methanol and natural gas in dual-fuel mode. According to the results, the methanol induced to a faster burning rate, improved the brake thermal efficiency, and reduced the equivalent brake specific fuel consumption. In case of Diesel cycle. Shan et al. (2016) investigated the effects of exhaust gas recirculation on combustion and emission characteristics of the Diesel engine fuelled with direct-injected diesel and port-injected biogas. The results showed that, when the exhaust gas recirculation rate increases, the combustion phase retards and the ignition delay in the engine gets prolonged. Karagöz et al. (2016) conducted a study using portinjected hydrogen and direct-injected diesel in the Diesel cycle and concluded that the brake thermal efficiency was decreasing with the increase of hydrogen in the mixture.

Up to date from preview literature review, no scientific works were published analysing dual-fuel mode in the PHEV using biofuels. To address this gap, this study aims to evaluate the possibility of replacing the single-fuel spark-ignition engine (SFSIE) of the series PHEV Chevrolet Volt II Generation powered by gasoline with the ICE powered by biogas and bioethanol from sugarcane, operating in dual-fuel mode. For this analysis, the Well-to-Wheel (WTW) emissions will be analysed through the Well-to-Pump (WTP), Tank-to-Wheel (TTW) emissions and electricity mix emissions. The energy efficiency of the Chevrolet Volt operating modes will also be analysed, and the energy-ecological efficiency of the ICE fuelled with different fuels in single-fuel and dual-fuel mode will be determined. Also, the bioethanol and biogas mass flow will be calculated for operation in dual-fuel mode. It is expected that the contributions of this article will fortify the environmental criteria that can enable decision-making to promote more sustainable end environmentally friendly vehicle technologies. 


\section{Methodology}

The series PHEV Chevrolet Volt 2016 II Generation was selected to evaluate the impacts on health and the environment through the analysis of the energy efficiency and the energy-ecological efficiency associated with an assessment of the WTW emissions considering the WTP, TTW and electricity mix emissions, aiming to replace the single-fuel spark-ignition engine (SFSIE) fuelled with Brazilian gasoline $(27 \%$ ethanol) by the dual-fuel spark-ignition engine (DFSIE) fuelled with sugarcane biogas and bioethanol. The GREET software will be used to evaluate the WTP emissions of the Brazilian sugarcane bioethanol and biogas production pathways. Besides that, the mass flow for bioethanol and biogas for dual-fuel operation will be calculated. So, this item will be divided into six sections: the section 2.1 describes the operating modes of the Chevrolet Volt; the section 2.2 presents the estimative of mass flow rate of sugarcane biogas and bioethanol for the DFSIE; the section 2.3 shows the calculation of energy efficiency of the series PHEV operating modes; the section 2.4 demonstrates the simulation of gasoline A, bioethanol and biogas combustion on GASEQ software; the section 2.5 demonstrates the estimation of the human toxicity and the global warming indicator and the calculation of the energy-ecological efficiency of the PHEV; the section 2. shows the WTP emissions of the Brazilian sugarcane bioethanol and biogas production pathways, the TTW emissions of the series PHEV with the SFSIE and with the DFSIE fuelled with sugarcane biogas and bioethanol, and the electricity mix emissions, to calculate the WTW emissions; and the section 2.7 shows the parameters adopted in this study.

\subsection{Series PHEV Operating Modes}

The Chevrolet Volt 2016 II Generation has four operating modes: electric vehicle mode operating with one motor (EVM-1M); electric vehicle mode operating with 2 motors (EVM-2M); extended-range mode with 1 motor (ERM-1M); and extended-range mode with 2 motors (ERM-2M). In the EVM-1M operating mode, the series PHEV operates as a pure EV, where the battery provides all the power that the vehicle needs (Fig. 1). In this mode, the vehicle receives electric power through the charger, and it is stored in the battery. The battery provides alternating current that is transformed into direct current by the inverter, which supply the electric motor (EM). The EM transmits power to the transmission system through a gear set consisting of ring gear, planetary gear, and solar gear. This mode presents better efficiency in lower speeds and distances.
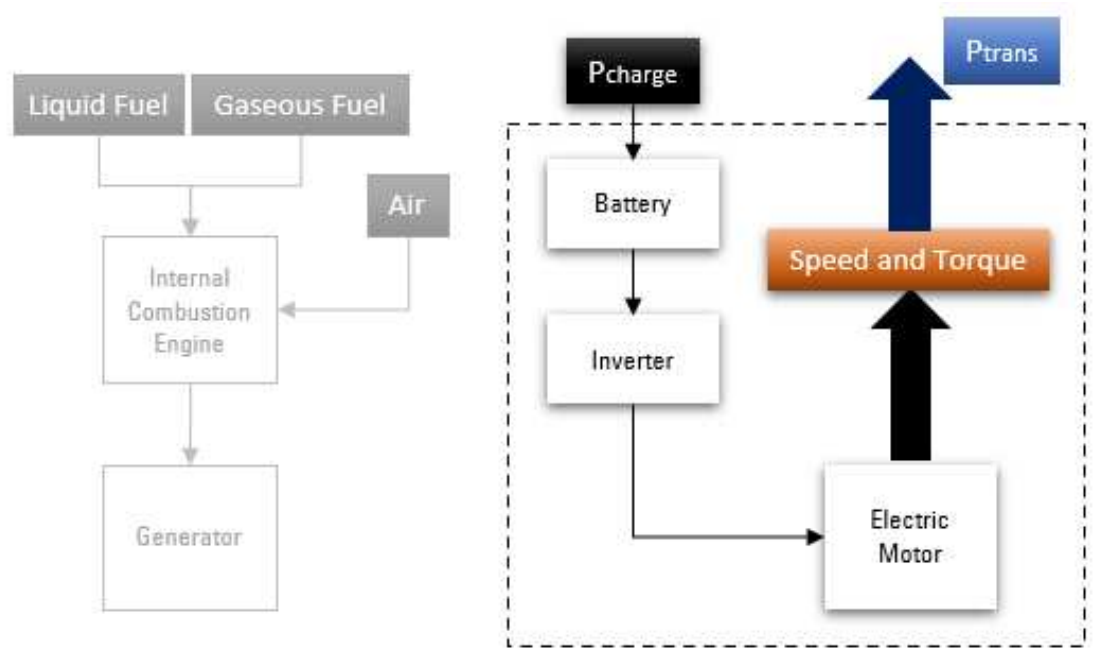

Figure 1. EVM-1M operating mode of the series PHEV Chevrolet Volt. 
In the EVM-2M operating mode, the generator turns into an auxiliary electric motor. It happens when the generator couples to the ring gear, which is inside of the EM (Fig. 2). In this mode, the electric power provided by the charger and stored in the battery powers both EM and generator. The generator coupled to the ring gear provides power to the EM and, depending on the battery state of charge and the driver's need, the remaining energy is directed from the EM to recharge the battery. Here, the EM speed request reduces with the actuation of the generator.

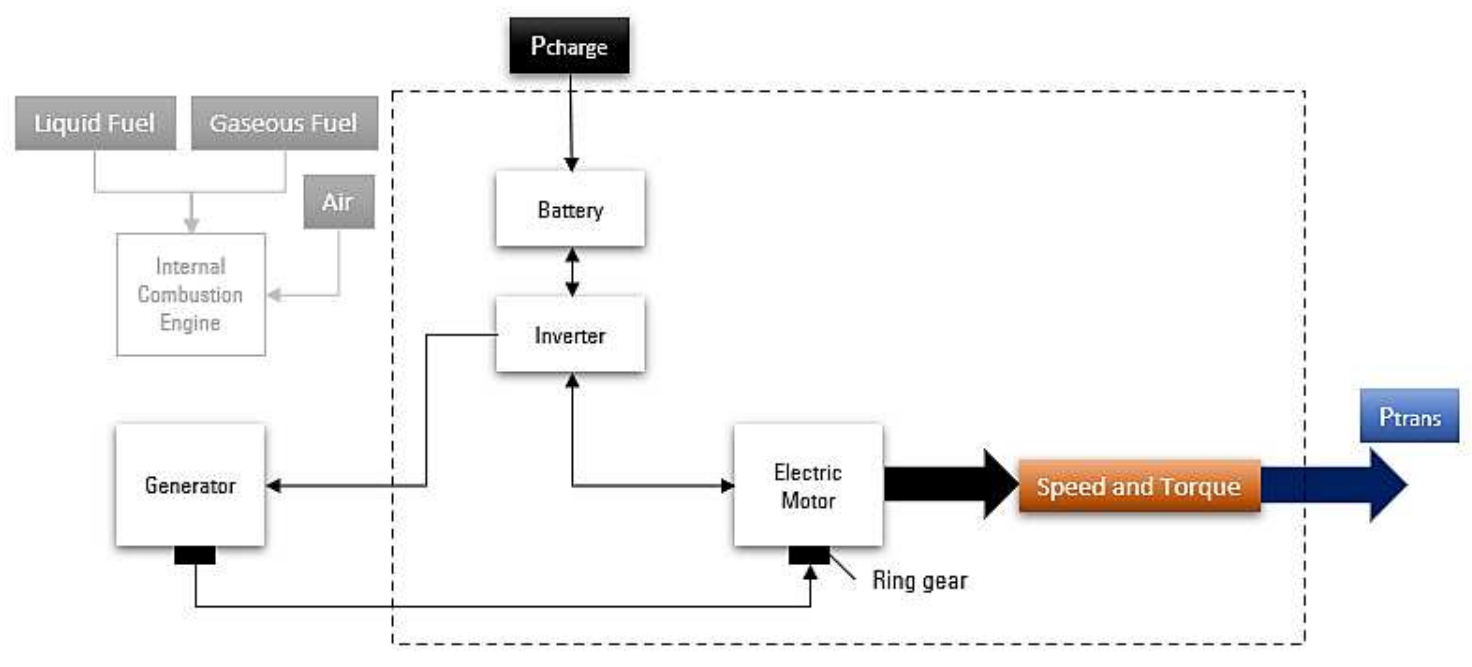

Figure 2. EVM-2M operating mode of the series PHEV Chevrolet Volt.

When the battery reaches the minimum state of charge level, the series PHEV no longer operates as an EV until it is plugged to the charger again. Then, the ICE starts, and the series PHEV operates in ERM-1M mode, which has only one EM operating, as shown in Fig. 3. In this study, as already mentioned, the ICE operates in dual-fuel mode, being fuelled with a gaseous fuel (sugarcane biogas), a liquid fuel (sugarcane bioethanol) and air, releasing exhaust gases from combustion. In this mode, the ICE is coupled to the generator, which only has the function of transforming the mechanical energy provided by the ICE in electrical energy to power the EM. Here, the battery reached the minimum state of charge limit, but still provides power to the EM when an additional power is needed. The advantage of the ERM-1M is that the ICE only couples to the generator, allowing the vehicle to operate in low speed in city driving. 


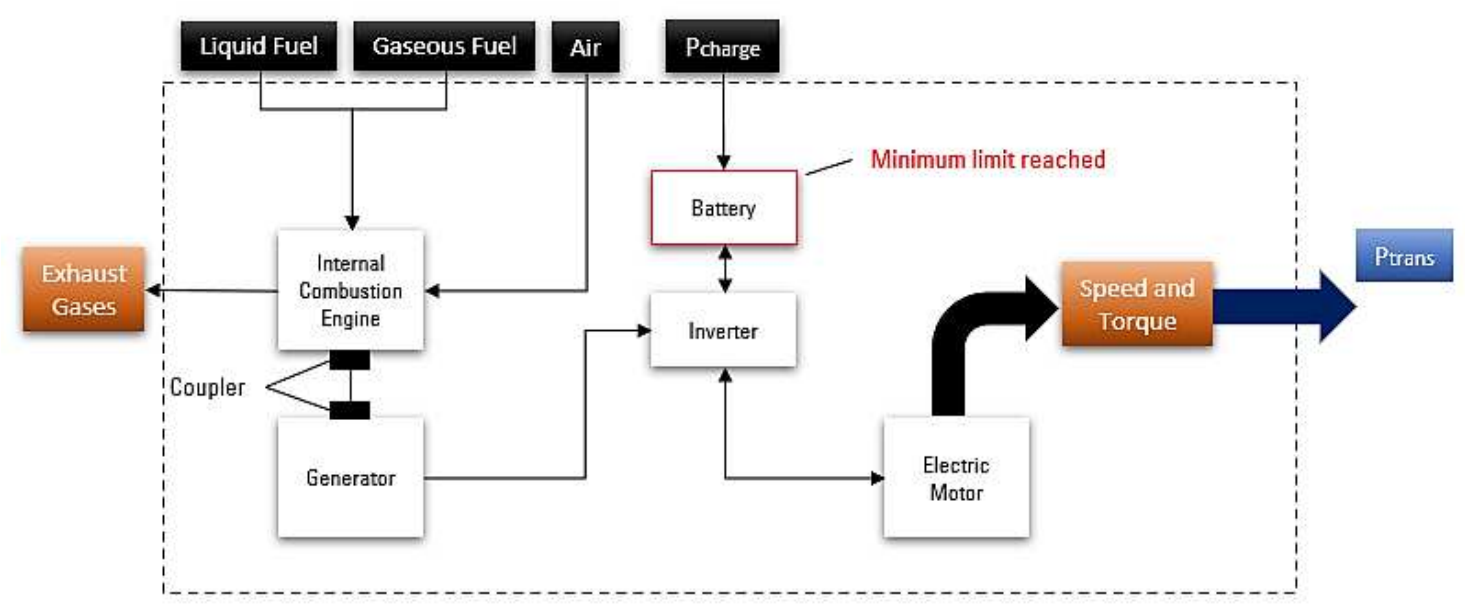

Figure 3. ERM-1M operating mode of series PHEV Chevrolet Volt.

To increase the vehicle efficiency between $10 \%$ and $15 \%$ in the highways, the Chevrolet Volt combines power of the EM and the generator as an auxiliary motor, initiating the ERM-2M operating mode. In this mode, the ICE decouples from the generator and the generator couples to the ring gear of the EM (Fig. 4). The EM speed request reduces with the actuation of the generator, as in EV-2M operating mode. When the ICE and generator speeds are synchronized, they are coupled and the operation with two motors is achieved. An advantage of this mode is that ICE speed can be automatically adjusted to it optimal speed looking for more efficient operation, once the ICE speed is independent of the wheel speed. In case of more power needed, the ICE and the generator will supply the most part of power, and an additional power will be provided by the battery. In both ERM-1M and ERM-2M, the EM also recharge the battery when there is energy remaining, depending on the battery state of charge and the driver's need.

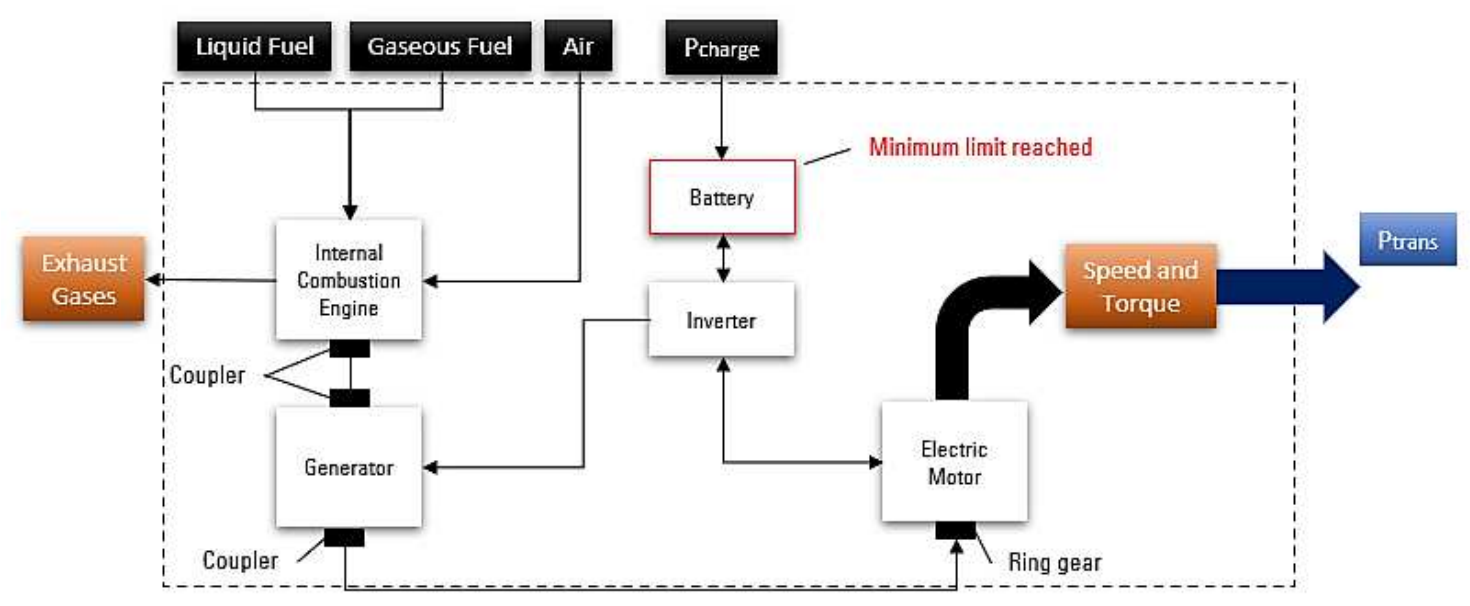

Figure 4. ERM-2M operating mode of series PHEV Chevrolet Volt.

\subsection{Mass flow rate of bioethanol and biogas in dual-fuel mode}

When the engine is powered by two fuels, it is necessary to consider the proportion of each fuel injected and its LHV. The biogas mass flow rate of the DFSIE can be calculated as shown in Eq. (1). 
$\dot{m}_{\text {biogas }}=\frac{z \times P}{B T E_{\text {dual-fuel }}\left[(1-z) \times L H V_{\text {bioethanol }}+z \times L H V_{\text {biogas }}\right]}$

Where, $B T E_{\text {dual-fuel }}$ is the brake thermal efficiency of the DFSIE; $\mathrm{P}$ is the vehicle power, in $\mathrm{kW}$; $\dot{m}_{\text {biogas }}$ is the biogas flow required, in $\mathrm{kg} / \mathrm{s} ; L H V_{\text {biogas }}$ is the low heating value of biogas, in $\mathrm{kJ} / \mathrm{kg}$; $L H V_{\text {bioethanol }}$ is the low heating value of bioethanol, in $\mathrm{kJ} / \mathrm{kg} ; \mathrm{z}$ represents the proportion of bioethanol replaced by biogas, whose value varies between $0 \%-100 \%$, with $\mathrm{z}=0 \%$ normal operation with ethanol and $\mathrm{z}>0 \%$ dual-fuel mode operation with biogas. According to [17]), the BTE dual-fuel is $36.1 \%$ for $\mathrm{z}=50 \%$, considering wide-open throttle (WOT) and $1800 \mathrm{rpm}$ in the spark-ignition engine.

The bioethanol mass flow rate, in $\mathrm{kg} / \mathrm{s}$, of the DFSIE can be obtained from Eq. (2).

$$
\dot{m}_{\text {bioethanol }}=\frac{\frac{P}{\text { BTE dual-fuel }}-\left(\dot{m}_{\text {biogas }} \times L H V_{\text {biogas }}\right)}{L H V_{\text {bioethanol }}}
$$

\subsection{Energy efficiency of series PHEV}

The energy efficiency is the amount of energy needed to complete a process. It means that the less energy is needed, the greater is the vehicle's efficiency. For each operating mode of the series PHEV, the energy efficiency is calculated from a different way depending on each transmission power, as show in the following items.

\subsubsection{Electric Vehicle Mode - 1 Motor}

In this operating mode, the electric motor (EM) depends on the power provided by the battery. So, the transmission power is calculated considering the battery power that passes through the EM, as shown in Eq. (3).

$\eta_{\text {trans }}=\frac{P_{\text {trans }, E V M-1 M}}{P_{\text {bat }} \times \eta_{E M}}$

Where, $\eta_{\text {trans }}$ is the transmission efficiency; $P_{\text {trans,EVM-1M }}$ is the EVM-1M transmission power, in W; $P_{b a t}$ is the battery power that supplies the EM, in W; $\eta_{E M}$ is the EM efficiency. The battery power can be calculated through the Eq. (4).

$P_{b a t}=\frac{C_{b a t}}{R_{b a t}} \times S_{a v}$

Where, $C_{b a t}$ is the battery capacity, in $\mathrm{Wh} ; R_{b a t}$ is the battery range, in $\mathrm{km} ; S_{a v}$ is the average speed, adopted as $40 \mathrm{~km} / \mathrm{h}$ in urban roads (Contran, 2005).

In the EVM-1M, the only energy needed is provided by the charger that supplies the battery. Then, the EVM-1M energy efficiency can be calculated through Eq. (5).

$\eta_{E V M-1 M}=\frac{P_{\text {trans,EVM-1M }}}{P_{\text {charger }}}$

Where, $P_{\text {charger }}$ is the charger power, in $\mathrm{W}$, which can be calculated by dividing $P_{b a t}$ by the battery efficiency $\left(\eta_{b a t}\right)$, as shown in Eq. (6). 
$P_{\text {charger }}=\frac{P_{b a t}}{\eta_{b a t}}$

\subsubsection{Electric Vehicle Mode - 2 Motor}

In the EVM-2M, the EM depends on the power provided by the battery, but also the generator power, which operates as an auxiliary motor. Thus, the transmission power is calculated considering the battery and generator power, and the EM efficiency, as shown in Eq. (7).

$\eta_{\text {trans }}=\frac{P_{\text {trans }, E V M-2 M}}{\left(P_{\text {bat }}+P_{\text {gen }}\right) \times \eta_{E M}}$

Where, $P_{\text {trans,EVM }-2 M}$ is the EVM-2M transmission power, in W; $P_{\text {gen }}$ is the generator power, in W.

In this operating mode, the EM is powered by the energy provided by the charger and the generator power. So, the EVM-2M energy efficiency can be calculated through Eq. (8):

$\eta_{E V M-2 M}=\frac{P_{\text {trans }, E V M-2 M}}{P_{\text {charger }}+P_{\text {gen }}}$

\subsubsection{Extended-Range Mode - 1 Motor}

In this operating mode, the EM is mainly powered by the energy provided by the engine, and the battery supplies the EM when an auxiliary power is needed. So, the transmission power is calculated considering the power provided by the ICE that passes through the generator, which converts the mechanical energy into electrical energy, and supplies the EM, as shown in Eq. (9).

$\eta_{\text {trans }}=\frac{P_{\text {trans,ERM-1M }}}{\left(P_{I C E}+\eta_{\text {gen }}\right) \times \eta_{E M}}$

Where, $P_{I C E}$ is the ICE power, in W; $P_{\text {trans,ERM }-1 M}$ is the ERM-1M transmission power, in W; $\eta_{\text {gen }}$ is the generator efficiency.

For this operating mode, the EM is powered by the energy supplied by the fuel consumption and small power supplied by the charge, adopted as $30 \%$. So, the ERM-1M energy efficiency can be calculated as shown in Eq. (10).

$\eta_{E R M-1 M}=\frac{P_{\text {trans }, E R M-1 M}}{1000 \times\left(\dot{m}_{\text {biogas }} \times L H V_{\text {biogas }}+\dot{m}_{\text {bioethanol }} \times L H V_{\text {bioethanol }}\right)+0.3 \times P_{\text {charger }}}$

Where, $P_{\text {trans,ERM }-1 M}$ is the ERM-1M transmission power, in W; $P_{\text {charger }}$ is the charger power, in W.

\subsubsection{Extended-Range Mode-2 Motor}

In the ERM-2M, the EM is powered by the ICE and by the generator, which turns to operate as an auxiliary motor supplied by the battery. So, the transmission power in this mode $\left(P_{\text {trans,ERM-2M }}\right)$, in $\mathrm{W}$, can be calculated as shown in Eq. (11).

$\eta_{\text {trans }}=\frac{P_{\text {trans }, E R M-2 M}}{\left(P_{I C E}+P_{\text {gen }}+P_{\text {bat }}\right) \times \eta_{E M}}$ 
In this operating mode, the series PHEV is powered by the fuel consumption in the ICE, and by a small power provided by the charge that supplies the generator and the EM. Thus, the energy efficiency of the series PHEV operating on ERM-2M $\left(\eta_{E R M-2 M}\right)$ considers the energy supplied by the fuel consumption, the generator power and a small power provided by the charge, as shown in Eq. (12).

$\eta_{E R M-2 M}=\frac{P_{\text {trans }, E R M-2 M}}{1000 \times\left(\dot{m}_{\text {biogas }} \times L H V_{\text {biogas }}+\dot{m}_{\text {bioethanol }} \times L H V_{\text {bioethanol }}\right)+P_{\text {gen }}+0.3 \times P_{\text {charger }}}$

\subsection{Simulation of the combustion using GASEQ}

Through the simulation using GASEQ software it was possible to evaluate the combustion reaction of gasoline A (Eq. 13), bioethanol (Eq. 14), and biogas with $60 \% \mathrm{CH}_{4}$ and $40 \% \mathrm{CO}_{2}$ [19] (Eq. 15), considering an air excess coefficient equal to $30 \%$, for gasoline-air and bioethanol-air mixtures, and $40 \%$ for biogas-air mixture [20]. The fuel-air mixture for gasoline, bioethanol, and biogas were analysed separately and after was applied the proportion of each fuel, considering SFSIE BTE for gasoline A and Brazilian gasoline (27\% ethanol), and DFSIE BTE for bioethanol and biogas.

$$
\begin{aligned}
& \mathrm{C}_{8} \mathrm{H}_{18}+16.25\left(\mathrm{O}_{2}+3.773 \mathrm{~N}_{2}\right) \rightarrow 8.0 \mathrm{CO}_{2}+3.60 \mathrm{O}_{2}+8.93 \mathrm{H}_{2} \mathrm{O}+61.16 \mathrm{~N}_{2}+0.30 \mathrm{NO}_{x} \\
& \mathrm{C}_{2} \mathrm{H}_{5} \mathrm{OH}+3.90\left(\mathrm{O}_{2}+3.773 \mathrm{~N}_{2}\right) \rightarrow 1.86 \mathrm{CO}_{2}+0.86 \mathrm{O}_{2}+2.88 \mathrm{H}_{2} \mathrm{O}+14.64 \mathrm{~N}_{2}+0.16 \mathrm{NO}_{x} \\
& 0.60 \mathrm{CH}_{4}+0.40 \mathrm{CO}_{2}+1.6\left(\mathrm{O}_{2}+3.773 \mathrm{~N}_{2}\right) \rightarrow \mathrm{CO}_{2}+0.39 \mathrm{O}_{2}+1.20 \mathrm{H}_{2} \mathrm{O}+6.03 \mathrm{~N}_{2}+0.02 \mathrm{NO}_{x}
\end{aligned}
$$

\subsection{Energy-ecological efficiency}

The energy-ecological efficiency $(\varepsilon)$ is the name of the method proposed by Cârdu and Baica (2001) (Eq. 16) to consider the potential of air pollution and the efficacy in converting fuel into energy (Carneiro and Gomes, 2019). Through this method it is possible to estimate the human toxicity and the global warming indicators, as shown in Eq. (17) and (18).

$$
\begin{aligned}
& \varepsilon=\left[c \frac{\eta}{\eta+\Pi} \ln (K \pm \Pi)\right]^{n} \\
& \Pi_{G W}=\frac{f_{\text {CO2 eq }}}{L H V_{\text {fuel }}} \\
& \Pi_{H T}=\frac{f_{1,4 D C B e q}}{L H V_{\text {fuel }}}
\end{aligned}
$$

Where, $\Pi_{G W}$ considers the emissions that contribute to global warming, expressed in $\mathrm{kg}$ eq pollutant $/ \mathrm{MJ}_{\text {fuel }}$; and $\Pi_{\mathrm{HT}}$ considers the emissions that contribute to human toxicity, expressed in $\mathrm{kg} 1.4 \mathrm{DCB} \mathrm{eq}_{\mathrm{eq}} / \mathrm{kg}_{\text {fuel }}$, where 1.4-dichlorobenzene is a substance used to calculate the level of human toxicity [22]. The equivalent carbon dioxide emission factor $\left(f_{\mathrm{CO} 2 \mathrm{eq}}\right)$ and the equivalent 1.4-dicholobenzene emission factor $\left(f_{1,4 D C B e q}\right)$ can be calculated through the Eq. (19) and (20), as follows:

$$
\begin{aligned}
& f_{\mathrm{CO} 2 \mathrm{eq}}=f_{\mathrm{CO} 2}+28 f_{\mathrm{CH} 4}+265 f_{\mathrm{N} 2 \mathrm{O}} \\
& f_{1,4 D C B e q}=4.54 f_{\mathrm{SO}_{2}}+56.71 f_{\mathrm{NOX}}+38.75 f_{P M}
\end{aligned}
$$

The specie emission factor $\left(f_{\text {specie }}\right)$ is the emission factor of each species resulting from the combustion of the air-fuel mixture, in $\mathrm{kg}_{\text {specie }} / \mathrm{kg}_{\text {fuel }}$, calculated by Eq. (21): 
$f_{\text {specie }}=\frac{\left(n_{\text {specie }} \times W_{\text {specie }}\right)}{\left(n_{\text {fuel }} \times W_{\text {fuel }}\right)}$

The pollution indicator, $\Pi$, is compound by $\Pi_{\mathrm{HT}}$ and by $\Pi_{\mathrm{GW}}$, and is calculated through Eq. (22), expressed in $\mathrm{kg}_{\text {eq pollutant }} / \mathrm{MJ}_{\text {fuel }}$ :

$\Pi=0.742 \Pi_{H T}+0.258 \Pi_{\mathrm{GW}}$

Finally, the energy-ecological efficiency can be obtained through Eq. (23), applying $c, K$ and $n$ constant values considered by Carneiro and Gomes (2019):

$\varepsilon=\left[2.01 \frac{\eta}{\eta+\Pi} \ln (1.645 \pm \Pi)\right]^{1.7}$

\subsection{Well-to-pump, tank-to-wheel, well-to-wheel emissions and electricity mix}

The WTW emissions consider the emission since the sugarcane plantation until the consumption by the vehicle and its exhaust gases. To calculate the WTW emissions, the WTP and the TTW were evaluate and then summed. As the vehicle analysed in this study is a series PHEV, the electricity mix generation emissions will also be summed in the WTW results. First, the Brazilian sugarcane bioethanol and biogas production pathway were analysed through GREET software to simulate the emissions of the sugarcane plantation and the bioethanol and biogas production until their availability at the supply pump. Then, the TTW were analysed considering the point where the vehicle is filled with fuel until the exhaust gases are discarded. Three electricity mix were considered to calculate the electric vehicle mode emissions.

\subsubsection{Well-to-Pump emissions}

The GREET software was used to analyse the WTP emissions from Brazilian sugarcane bioethanol and biogas production pathways. The measure units are in the international measurement system only for simulation proposes. First, the Brazilian sugarcane bioethanol production was simulated through the existing process on GREET named as "Brazilian Sugarcane to Ethanol with Electricity Export". This process was changed to "Brazilian Sugarcane to 1G2G Ethanol with Vinasse Allocation" and the inputs and outputs applied to create it is shown in Table 1, considering $1 \mathrm{gal}$ of ethanol. The lime was added for $\mathrm{pH}$ adjustment proposes of the sugarcane juice. Thus, the pathway for ethanol production from sugarcane with vinasse co-production was created. After that, a process was created to simulate the transportation of the ethanol produced in Brazil to the refuelling station, and then was named as "Ethanol Transportation to Refuelling Station - Produced and Used in Brazil" (Table 2). For this process, the conventional diesel that power the heavy-duty trucks was considered to be imported from USA to Brazil because of its amount imported into Brazil in 2019 , which was $10,778,100 \mathrm{~m}^{3}$ while the national production was $40,914,849 \mathrm{~m}^{3}$ (ANP, 2020).

Table 1. Inputs and outputs inserted to create the "Brazilian Sugarcane to 1G2G Ethanol with Vinasse Allocation" process

\begin{tabular}{l|c|c|c}
\multicolumn{1}{c|}{ Inputs } & Value & Unit & Source Type \\
\hline Sugarcane straw & $2.21 \mathrm{e}^{-3}$ & ton & Primary resource \\
\hline Sugarcane bagasse & $7.21 \mathrm{e}^{-3}$ & ton & Primary resource \\
\hline Sugarcane & $4.67 \mathrm{e}^{-2}$ & ton & Output of a previous process \\
\hline
\end{tabular}




\begin{tabular}{l|c|c|c}
\hline Lime $(\mathrm{CaO})$ & $4.11 \mathrm{e}^{-5}$ & ton & Pathway: Lime production from limestone \\
\hline Residual oil & $3.00 \mathrm{e}^{-3}$ & mmBTU & Pathway: Residual oil (petroleum) from crude oil \\
\hline \multicolumn{1}{c|}{ Outputs } & Value & Unit & Losses: $0 \%$ \\
\hline Ethanol (main output) & 1.00 & gal & Energy-based allocation factor: $0.0 \%$ \\
\hline Vinasse & $4.73 \mathrm{e}^{-2}$ & $\mathrm{~m}^{3}$ &
\end{tabular}

Table 2. "Ethanol Transportation to Refuelling Station - Produced and Used in Brazil" process.

\begin{tabular}{l|c|c|c|c}
\hline Transportation & Distance Value & Unit & Origin - Destination & Fuel \\
\hline Heavy-duty truck & 350 & $\mathrm{mi}$ & Ethanol plant - Bulk terminal & Conventional diesel from USA to Brazil \\
\hline Heavy-duty truck & 30 & $\mathrm{mi}$ & Bulk terminal - Refuelling station & Conventional diesel from USA to Brazil
\end{tabular}

To create the sugarcane biogas production pathway, the resources was added to GREET database, as shown in Table 3. The proportion of $12.5 \mathrm{~m}^{3}$ vinasse $/ \mathrm{m}^{3}$ ethanol and the vinasse allocation factor of 0.94 were considered. The "Biogas Production from Vinasse via Anaerobic Digestion" process was created considering the proportion of $23.72 \mathrm{~m}^{3}$ biogas $/ \mathrm{m}^{3}$ vinasse, as shown in Table 4 . The biogas transportation is conducted from sugarcane bioethanol plant to the refuelling station via pipeline, which natural gas pipeline parameters were reused for biogas, considering 50 miles, approximately, with $14 \%$ urban share. Thus, the "Vinasse Biogas Production to Brazilian Refuelling Station" pathway was created.

Table 3. Resources added to create the sugarcane biogas production pathway.

\begin{tabular}{|l|c|c|c|c|}
\hline \multicolumn{1}{|c|}{ Resource } & LHV $(\mathbf{M J} / \mathbf{k g})$ & Density $\left(\mathbf{k g} / \mathbf{m}^{3}\right)$ & Carbon Ratio $(\%)$ & Sulphur Ratio $(\boldsymbol{\%})$ \\
\hline Vinasse & - & 1.031 & 1.960 & 0.0142 \\
\hline Vinasse biogas & 27.4 & 0.784 & 0.558 & 0.0189 \\
\hline
\end{tabular}

Table 4. "Biogas Production from Vinasse via Anaerobic Digestion" process.

\begin{tabular}{ll|c|c|c}
\multicolumn{1}{c|}{ Inputs } & Value & Unit & Source Type \\
\hline Electricity & & 0.46 & $\mathrm{kWh}$ & Single pathway: Distributed - Brazil Mix \\
\hline Vinasse & & $1.04 \mathrm{e}^{-6}$ & $\mathrm{~km}^{3}$ & Output of a previous process \\
\hline \multicolumn{1}{c|}{ Outputs } & Value & Unit & \\
\hline Biogas & & $2.74 \mathrm{e}^{-5}$ & $\mathrm{~km}^{3}$ & Losses: $2 \%$ (Evaporation: $60 \% \mathrm{CH}_{4} ; 40 \% \mathrm{CO}_{2}$
\end{tabular}

Finally, the WTP emissions for sugarcane bioethanol and biogas were calculated through Eq. (24) and (25), respectively. For bioethanol, the emissions since the production until the transport were considered. For biogas, the percentage of losses of 0-2\% [24] during the production stage were considered.

$$
\begin{aligned}
& W T P_{\text {bioethanol }}=\frac{f C O_{2 \text { eq bioethanol }} \times E_{\text {consump }}}{L H V_{\text {bioethanol }} \times \rho_{\text {bioethanol }}} \\
& W T P_{\text {biogas }}=\left(\frac{f C O_{2 \text { eq trans biogas }} \times E_{\text {consump }}}{L H V_{\text {biogas }} \times \rho_{\text {biogas }}}\right)+\% \text { Losses } \times\left(\frac{f C O_{2 \text { eq prod biogas }} \times E_{\text {consump }}}{L H V_{\text {biogas }} \times \rho_{\text {biogas }}}\right)
\end{aligned}
$$

Where, $W T P_{\text {bioethanol }}$ is the WTP emissions related to the sugarcane bioethanol production, in $\mathrm{gCO}_{2}$ eq $/ \mathrm{km} ; \mathrm{fCO}_{2}$ eq bioethanol is the equivalent $\mathrm{CO}_{2}$ eq emission factor of the bioethanol production, in $\mathrm{kgCO}_{2}$ eq $/ \mathrm{m}^{3}$ bioethanol; $\rho_{\text {bioethanol }}$ is the bioethanol density, in $\mathrm{kg} / \mathrm{m}^{3} ; W T P_{\text {biogas }}$ is the WTP emissions related to the vinasse biogas, in $\mathrm{gCO}_{2} \mathrm{eq} / \mathrm{km} ; f C O_{2}$ eq trans biogas is the equivalent $\mathrm{CO}_{2}$ eq emission factor of the biogas transportation, in $\mathrm{kgCO}_{2 \text { eq }} / \mathrm{m}^{3}$ biogas; $\rho_{\text {biogas }}$ is the vinasse biogas density, in $\mathrm{kg} / \mathrm{m}^{3} ; \%$ Losses is the percentage of losses during the biogas production process; $f \mathrm{CO}_{2}$ eq prod is the $\mathrm{CO}_{2}$ eq emission factor of 
the biogas production, in $\mathrm{kgCO}_{2} \mathrm{eq} / \mathrm{m}^{3}$ biogas. The $E_{\text {consump }}$ is the energy consumed by the ICE of the Chevrolet Volt, considering gasoline A as fuel, according to the manufacturer's specifications, and can be expressed through the Eq. (26).

$E_{\text {consump }}=\frac{L H V_{\text {gasoline A }} \times \rho_{\text {gasoline A }} \times F C_{\text {gasoline A }}}{1000}$

Where, $E_{\text {consump }}$ is the energy consumption needed by the ICE, in $\mathrm{MJ} / \mathrm{km} ; L H V_{\text {gasoline } A}$ is the low heating value of the gasoline $\mathrm{A}$, in $\mathrm{MJ} / \mathrm{kg} ; \rho_{\text {gasoline } A}$ is the gasoline A density, in $\mathrm{kg} / \mathrm{m}^{3} ; F C_{\text {gasoline } A}$ is the gasoline A consumption provided by the manufacturer, in $1 / \mathrm{km}$.

\subsubsection{Tank-to-wheel emissions}

The TTW emissions of the SFSIE and the DFSIE can be calculated considering the fuel consumption, the $f_{\mathrm{CO} 2 \text { eq }}$ related to fuel combustion, and the fuel density, as shown in Eq. (27) and (28), respectively.

$T T W_{S}=f_{\text {CO2 eq fuel }} \times \rho_{\text {fuel }} \times F C_{\text {fuel }}$

$T T W_{D}=z\left(f_{\text {CO2 eq biogas }} \times \rho_{\text {biogas }} \times F C_{\text {biogas }}\right)+y\left(f_{\text {CO2 eq bioethanol }} \times \rho_{\text {bioethanol }} \times F C_{\text {bioethanol }}\right)$

Where, $T T W_{S}$ is the tank-to-wheel emissions of the SFSIE, in $\mathrm{gCO}_{2 \mathrm{eq}} / \mathrm{km} ; f_{C O 2 \text { eq fuel }}$ is the equivalent $\mathrm{CO}_{2}$ eq emission factor resulted from the fuel combustion, in $\mathrm{kgCO}_{2}$ eq $/ \mathrm{kg}$ fuel; $\rho_{\text {fuel }}$ is the fuel density, in $\mathrm{kg} / \mathrm{m}^{3} ; F C_{\text {fuel }}$ is the fuel consumption, in $1 / \mathrm{km} ; T T W_{D}$ is the DFSIE tank-to-wheel emissions, in $\mathrm{gCO}_{2 \mathrm{eq}} / \mathrm{km}$; $\mathrm{FC}_{\text {biogas }}$ is the vehicle biogas consumption, in $1 / \mathrm{km}, \mathrm{FC}_{\text {bioethanol }}$ is the vehicle bioethanol consumption, in $1 / \mathrm{km} ; z$ is the biogas proportion replacing bioethanol; $y$ is the proportion of bioethanol in the dual-fuel mode $(y=1-z)$. For TTW emissions of SFSIE, the proportion of bioethanol replaced is zero, so $z$ is equal to 0 . For TTW emissions of DFSIE, the $z$ value applied is $50 \%$ as considered by [17].

As previously said, the fuel consumption provided by Chevrolet is related to the gasoline A consumption. So, it is necessary to calculate the bioethanol consumption in the ICE through the energy consumption calculated previously in Eq. (26). Then, the bioethanol and biogas consumptions were measured individually through the energy needed in the ICE, as shown in Eq. (29).

$F C_{\text {fuel }}=\frac{1000 \times E_{\text {consump }}}{L H V_{\text {fuel }} \times \rho_{\text {fuel }}}$

For comparative purposes, the fuel consumption and the TTW emissions will be calculated for Brazilian gasoline (27\% ethanol) through Eq. (30) and (31), respectively.

$$
\begin{aligned}
& F C_{B R \text { gasol }}=\frac{1000 \times E_{\text {consump }}}{0.73\left(L H V_{\text {gasoline A }} \times \rho_{\text {gasoline A }}\right)+0.27\left(L H V_{\text {bioethanol }} \times \rho_{\text {bioethanol }}\right)} \\
& T T W_{B R \text { gasol }}=\left[0.73\left(f_{\text {CO2 eq gasoline A }} \times \rho_{\text {gasoline A }}\right)+0.27\left(f_{\text {CO2 eq bioethanol }} \times \rho_{\text {bioethanol }}\right)\right] \times F C_{B R \text { gasol }}
\end{aligned}
$$

Where, $F C_{B R \text { gasol }}$ is the vehicle Brazilian gasoline consumption, in $1 / \mathrm{km}$; TTW $W_{B R}$ gasol is the TTW emissions of the Brazilian gasoline, in $\mathrm{gCO}_{2} \mathrm{eq} / \mathrm{km}$.

\subsubsection{Electricity mix}

In this item, the electricity mix emissions were analysed for the series PHEV Chevrolet Volt, considering its electrical energy consumption of $0.202 \mathrm{kWh} / \mathrm{km}$ and three electricity mixes: Brazil electricity mix, Spain electricity mix and EU electricity mix. According to EPE (2020b), the Brazilian mix generated about 83,361 
GWh of electricity from coal, natural gas, oil-fuel and diesel oil, emitting $416.3 \mathrm{gCO}_{2 \mathrm{eq}} / \mathrm{kWh}$, in 2019, refered to the national interconnected system. At the same year, the Spanish mix emitted $190 \mathrm{gCO}_{2 \mathrm{eq}} / \mathrm{kWh}$, considering the electricity generation (REE, 2020). IRENA (2017) provided the EU electricity mix emission of $75 \mathrm{gCO}_{2 \mathrm{eq}} / \mathrm{km}$. Through these data, the electricity mix emissions can be calculated by Eq. (32).

$E_{\text {electricitymix }}=f \mathrm{CO}_{2 \text { eq electric mix }} \times E E_{\text {consump }}$

Where, $E_{\text {electricity mix }}$ is the electricity mix emissions, in $\mathrm{gCO}_{2 \mathrm{eq}} / \mathrm{km} ; f \mathrm{fO}_{2}$ eq electric mix is the $\mathrm{CO}_{2}$ eq emission factor of the electricity mix, in $\mathrm{gCO} 2 \mathrm{eq} / \mathrm{kWh} ; E E_{\text {consump }}$ is the electrical energy consumption of the series PHEV Chevrolet Volt, in $\mathrm{kWh} / \mathrm{km}$.

\subsection{Parameters and considerations adopted in the study}

The considerations and parameters adopted in this study to determine the energy efficiency of the series PHEV and evaluate the replacement of the SFSIE fuelled with gasoline by the DFSIE fuelled with sugarcane biogas and bioethanol are presented in Table 5.

Table 5. Parameters and considerations adopted.

\begin{tabular}{|c|c|c|c|}
\hline Parameter & Value & Unit & Reference \\
\hline Density - Anhydrous ethanol & 791 & $\mathrm{~kg} / \mathrm{m}^{3}$ & ANP (2019) \\
\hline Density - Sugarcane vinasse & 1,031 & $\mathrm{~kg} / \mathrm{m}^{3}$ & Prasad \& Shih (2016) \\
\hline Density - Vinasse biogas & 0.784 & $\mathrm{~kg} / \mathrm{m}^{3}$ & Neto et al. (2017) \\
\hline Density - Gasoline A & 742 & $\mathrm{~kg} / \mathrm{m}^{3}$ & ANP (2019) \\
\hline Density - Brazilian gasoline & 754 & $\mathrm{~kg} / \mathrm{m}^{3}$ & ANP (2019) \\
\hline Sulphur Ratio - Sugarcane vinasse & 0.0142 & $\%$ & Rahman et al. (2018) \\
\hline Sulphur Ratio - Vinasse biogas & 1.89 & $\%$ & Rahman et al. (2018) \\
\hline Carbon Ratio - Sugarcane vinasse & 1.955 & $\%$ & Siles et al. (2011) \\
\hline Carbon Ratio - Vinasse biogas & 55.84 & $\%$ & Leme and Seabra (2017) \\
\hline LHV - Anhydrous ethanol & 28,261 & $\mathrm{~kJ} / \mathrm{kg}$ & $\operatorname{ANP}(2019)$ \\
\hline LHV - Vinasse biogas & 27,400 & $\mathrm{~kJ} / \mathrm{kg}$ & Calculated by the authors \\
\hline LHV - Gasoline A & 43,543 & $\mathrm{~kJ} / \mathrm{kg}$ & ANP (2019) \\
\hline LHV - Brazilian gasoline & 39,356 & $\mathrm{kj} / \mathrm{kg}$ & $\operatorname{ANP}(2019)$ \\
\hline Proportion of vinasse from ethanol & 12.5 & $\mathrm{~m}^{3} / \mathrm{m}^{3}$ ethanol & Christofoletti et al. (2013) \\
\hline Proportion of biogas from vinasse & 23.72 & $\mathrm{~m}^{3}$ biogas $/ \mathrm{m}^{3}$ vinasse & Parsaee et al. (2019) \\
\hline Allocation factor & 0.94 & - & Calculated by the authors \\
\hline Power - Electric Motor & 111.109 & W & Chevrolet \\
\hline Power - Engine & 75316 & W & Chevrolet \\
\hline Power - Generator & 53690 & W & Chevrolet \\
\hline Transmission efficiency & 80 & $\%$ & Xue et al. (2014) \\
\hline Battery efficiency & 90 & $\%$ & Fathabadi (2018) \\
\hline Electric motor efficiency & 85 & $\%$ & Xue et al. (2014) \\
\hline Generator efficiency & 85 & $\%$ & Xue et al. (2014) \\
\hline Battery capacity & 18400 & Wh & Chevrolet \\
\hline All-electric range & 85 & $\mathrm{~km}$ & Chevrolet \\
\hline Electric energy consumption & 0.202 & $\mathrm{kWh} / \mathrm{km}$ & Chevrolet \\
\hline Average speed & 40 & $\mathrm{~km} / \mathrm{h}$ & Contran (2005) \\
\hline Fuel consumption - Gasoline & 0.0630 & $1 / \mathrm{km}$ & Chevrolet \\
\hline Molecular weight - Gasoline & 114 & $\mathrm{~g}$ & - \\
\hline
\end{tabular}




\begin{tabular}{|c|c|c|c|}
\hline Molecular weight - Ethanol & 46 & $\mathrm{~g}$ & - \\
\hline Molecular weight - Biogas & 60 & g & - \\
\hline Constant $-\mathrm{c}$ & 2.01 & - & Carneiro and Gomes (2019) \\
\hline Constant $-\mathrm{K}$ & 1.645 & - & Carneiro and Gomes (2019) \\
\hline Constant $-\mathrm{n}$ & 1.7 & - & Carneiro and Gomes (2019) \\
\hline Air excess coefficient - Biogas & 40 & $\%$ & Coronado et al. (2009) \\
\hline Air excess coefficient - Bioethanol & 30 & $\%$ & Coronado et al. (2009) \\
\hline Air excess coefficient - Gasoline A & 30 & $\%$ & Coronado et al. (2009) \\
\hline$\phi$ - Gasoline-air & 0.77 & - & Calculated by the authors \\
\hline$\phi-$ Bioethanol-air & 0.77 & - & Calculated by the authors \\
\hline$\phi-$ Biogas-air & 0.75 & - & Calculated by the authors \\
\hline $\mathrm{Z}$ value & 50 & $\%$ & da Costa et al. (2020) \\
\hline $\mathrm{BTE}_{\text {dual-fuel }}($ for $\mathrm{z}=50 \%)$ & 36.1 & $\%$ & da Costa et al. (2020) \\
\hline $\mathrm{BTE}_{\text {bioethanol }}$ & 25 & $\%$ & Balki et al. (2014) \\
\hline BTE $_{\text {gasoline }}$ & 23 & $\%$ & Balki et al. (2014) \\
\hline Brazil electricity mix & 416.3 & $\mathrm{gCO}_{2 \mathrm{eq}} / \mathrm{kWh}$ & EPE (2020b) \\
\hline Spain electricity mix & 190 & $\mathrm{gCO}_{2 \mathrm{eq}} / \mathrm{kWh}$ & REE (2020) \\
\hline EU electricity mix & 75 & $\mathrm{gCO}_{2 \mathrm{eq}} / \mathrm{kWh}$ & IRENA (2017) \\
\hline$\%$ Losses during biogas production & $0-2$ & $\%$ & Afrane and Ntiamoah (2011) \\
\hline
\end{tabular}

\section{Results and Discussion}

In this study, the mass flow rate of bioethanol and biogas were calculated, and the energy efficiency of each series PHEV operating mode was determined. The emission factors were determined to calculate the energy-ecological efficiency and the TTW emissions of the series PHEV with the DFSIE fuelled with sugarcane bioethanol and biogas. Besides that, the WTP emissions were analysed by using the GREET software to simulate the Brazilian sugarcane bioethanol and biogas production pathways. The electrical energy emissions were calculated considering the Brazil, Spain, and European Union electricity mixes, and then the WTW emissions were evaluated.

\subsection{Bioethanol and biogas mass flows in dual-fuel mode}

The bioethanol and biogas mass flows in the DFSIE were calculated, considering $\mathrm{z}$ value equal to $50 \%$. The Eq. (1) was applied to calculate the biogas mass flow of the DFSIE, adopting $36,1 \%$ BTE $E_{\text {dual-fuel }}$ by da Costa et al. (2020). Then, the bioethanol mass flow was measured trough Eq. (2). The values found for bioethanol and biogas mass flows were $0.00375 \mathrm{~kg} / \mathrm{s}$ or $13.49 \mathrm{~kg} / \mathrm{h}$, each.

\subsection{Energy efficiency of series PHEV}

As explained in the previous items, the operating modes of the series PHEV depend on the sources that power each mode. Thus, the transmission power and the energy efficiency were calculated for each operating mode through Eq. (3-12), and the results are shown in Table 6. In EVM-1M, the high efficiency can be explained by the direct conversion of the electrical power into mechanical power, approaching the efficiency of a purely electric vehicle. The EVM-2M presented greater efficiency than the EVM-1M because of the assistance of the generator power, which turns the ring gear and provides mechanical energy to the EM. In the case of the ERM-1M, the efficiency falls sharply due to the conversion of mechanicalelectrical-mechanical power provides by the engine-generator-motor-transmission gear set. Finally, in the ERM-2M, the energy efficiency increased by $14.7 \%$ due to the combination of the ICE and the generator, resulting from the synchronization of both speeds. 
Table 6. Transmission power and energy efficiency of the series PHEV operating modes.

\begin{tabular}{c|llc}
\hline Operating Mode & Parameter & Value & Unit \\
\hline \multirow{2}{*}{ EVM-1M } & $P_{\text {trans,EVM-1M }}$ & 5,888 & $\mathrm{~W}$ \\
\cline { 2 - 4 } & $\eta_{E V M-1 M}$ & 61.3 & $\%$ \\
\hline \multirow{2}{*}{ EVM-2M } & $P_{\text {trans,EVM-2M }}$ & 42,397 & $\mathrm{~W}$ \\
\cline { 2 - 4 } & $\eta_{\text {EVM-2M }}$ & 67.0 & $\%$ \\
\hline \multirow{2}{*}{ ERM-1M } & $P_{\text {trans,ERM-1M }}$ & 43,533 & $\mathrm{~W}$ \\
\cline { 2 - 3 } & $\eta_{\text {ERM-1M }}$ & 20.6 & $\%$ \\
\hline \multirow{2}{*}{ ERM-2M } & $P_{\text {trans,ERM-2M }}$ & 93,612 & $\mathrm{~W}$ \\
\cline { 2 - 3 } & $\eta_{E R M-2 M}$ & 35.3 & $\%$ \\
\hline
\end{tabular}

\subsection{Simulation on GASEQ and pollution indicators}

The bioethanol-air, biogas-air and gasoline A-air mixtures were analysed separately through simulation of Eq. (13-15) on GASEQ software to evaluate the pollution indicators of each mixture. Table 7-9 show the reactants and products species of each simulation, and the emission factors of the products related to the global warming and human toxicity indicators that were determined through Eq. (21).

Table 7. Reactants and products, and specie emission factors of the bioethanol-air mixture combustion.

\begin{tabular}{|c|c|c|c|}
\hline Reactants & No. Moles & Mol. Weight & \\
\hline $\mathrm{C}_{2} \mathrm{H}_{5}$ & 1.00 & 29 & \\
\hline $\mathrm{OH}$ & 1.00 & 17 & \\
\hline $\mathrm{O}_{2}$ & 3.90 & 32 & \\
\hline $\mathrm{N}_{2}$ & 14.71 & 28 & \\
\hline Products & No. Moles & Mol. Weight & $\boldsymbol{f}_{\text {specie }}$ \\
\hline $\mathrm{CO}_{2}$ & 1.86 & 44 & 1.78062 \\
\hline $\mathrm{CH}_{4}$ & 0.00 & 16 & $1.33461 \mathrm{e}^{-17}$ \\
\hline $\mathrm{N}_{2} \mathrm{O}$ & 0.00 & 44 & $7.17009 \mathrm{e}^{-05}$ \\
\hline $\mathrm{SO}_{2}$ & 0.00 & 64 & 0 \\
\hline $\mathrm{NO}_{\mathrm{x}}$ & 0.16 & 30 & 0.10326 \\
\hline $\mathrm{PM}$ & 0.00 & 12 & 0 \\
\hline
\end{tabular}

Table 8: Reactants and products, and specie emission factors of the biogas-air mixture combustion.

\begin{tabular}{|c|c|c|c|}
\hline Reactants & No. Moles & Mol. Weight & \\
\hline $\mathrm{CH}_{4}$ & 0.60 & 16 & \\
\hline $\mathrm{CO}_{2}$ & 0.40 & 44 & \\
\hline $\mathrm{O}_{2}$ & 1.60 & 32 & \\
\hline $\mathrm{N}_{2}$ & 6.04 & 28 & \\
\hline Combustion Products & No. Moles & Mol. Weight & $f_{\text {specie }}$ \\
\hline $\mathrm{CO}_{2}$ & 1.00 & 44 & 1.61571 \\
\hline $\mathrm{CH}_{4}$ & 0.00 & 16 & $6.96471 \mathrm{e}^{-23}$ \\
\hline $\mathrm{N}_{2} \mathrm{O}$ & 0.00 & 44 & $1.40849 \mathrm{e}^{-06}$ \\
\hline $\mathrm{SO}_{2}$ & 0.00 & 64 & 0 \\
\hline $\mathrm{NO}_{\mathrm{x}}$ & 0.02 & 30 & 0.019929 \\
\hline
\end{tabular}




\begin{tabular}{l|l|l|l|}
\hline PM & 0.00 & 12 & 0 \\
\hline
\end{tabular}

Table 9. Reactants and products, and specie emission factors of the gasoline A-air mixture combustion.

\begin{tabular}{l|c|c|c}
\hline Reactants & No. Moles & Mol. Weight \\
\cline { 1 - 3 } $\mathrm{C}_{8} \mathrm{H}_{18}$ & 1.00 & 114 & \\
\cline { 1 - 3 } $\mathrm{O}_{2}$ & 16.25 & 32 & \\
\hline $\mathrm{N}_{2}$ & 61.31 & 28 & \\
\hline Combustion Products & No. Moles & Mol. Weight & $\boldsymbol{f}_{\text {specie }}$ \\
\hline $\mathrm{CO}_{2}$ & 7.95 & 44 & 3.06841 \\
\hline $\mathrm{CH}_{4}$ & 0.00 & 16 & $1.00281 \mathrm{e}^{-20}$ \\
\hline $\mathrm{N}_{2} \mathrm{O}$ & 0.00 & 44 & $5.63895 \mathrm{e}^{-06}$ \\
\hline $\mathrm{SO}_{2}$ & 0.00 & 64 & 0 \\
\hline $\mathrm{NO}_{\mathbf{x}}$ & 0.30 & 30 & 0.07831 \\
\hline $\mathrm{PM}$ & 0.00 & 12 & 0 \\
\hline
\end{tabular}

The Eq. (19) and (20) were applied to calculate the $f_{C O 2 \text { eq }}$ and the $f_{1,4 D C B e q}$. Table 7 shows the values found for bioethanol, biogas, $50 \%$ bioethanol $+50 \%$ biogas, gasoline A and Brazilian gasoline. As can be seen, the highest $f_{\mathrm{CO} 2 ~ e q}$ value was found for gasoline A due to the number of moles of $\mathrm{CO}_{2}$ resulting in its combustion, with negligible value of $\mathrm{CH}_{4}$ and $\mathrm{N}_{2} \mathrm{O}$. On the other hand, the bioethanol presented the highest $f_{1,4 D C B e q}$ value. It is because of the $f_{N 2 O}$ produced by combustion of bioethanol that had the highest value among the $\mathrm{N}_{2} \mathrm{O}$ factors found for the other fuels.

Table 10. Carbon dioxide and 1.4-Dichorobenzene equivalent factors of the fuels analysed.

\begin{tabular}{lcc} 
Fuel & $\boldsymbol{f} \mathbf{C O}_{2 \text { eq }}(\mathbf{k g ~ C O}$ eq $/ \mathbf{k g}$ fuel $)$ & $\boldsymbol{f} \mathbf{1 . 4 - D C B ~}$ eq $(\mathbf{k g ~ 1 - 4 ~ D C B ~} \mathbf{~ e q} / \mathbf{k g}$ fuel $)$ \\
\hline Gasoline A & 3.0699 & 4.4411 \\
\hline Brazilian Gasoline & 2.7223 & 4.8232 \\
\hline Bioethanol & 1.7825 & 5.8561 \\
\hline Biogas & 1.6161 & 1.1302 \\
\hline 50\% Bioethanol + 50\% Biogas & 1.6993 & 3.4931 \\
\hline
\end{tabular}

Through these values, the $\Pi_{G W}$ and the $\Pi_{H T}$ were calculated through Eq. (17) and (18), and then the pollution indicator was measured through Eq. (22). The results are shown in Fig. 5. As expected, gasoline A and Brazilian gasoline resulted in the highest $\Pi_{G W}$ values due to their highest $f_{C O 2 \text { eq }}$ value, been $15.5 \%$ and $12.2 \%$ higher than the value found for $50 \%$ bioethanol $+50 \%$ biogas. The bioethanol presented the highest $\Pi_{H T}$ value, which is twice higher than gasoline A and 58.9\% higher than Brazilian gasoline. Also, the $\Pi_{H T}$ value found for bioethanol was $66.8 \%$ higher than that found for $50 \%$ bioethanol $+50 \%$ biogas, which application is the propose of this study. In the case of biogas, the lowest $\Pi_{H T}$ and $\Pi_{G W}$ were found, which were $66.8 \%$ and $3.3 \%$ lower than those values found for $50 \%$ bioethanol $+50 \%$ biogas, respectively.

The highest $\Pi$ value was found for bioethanol, 57.5\% higher than that found for $50 \%$ bioethanol $+50 \%$ biogas due to its $\Pi_{H T}$ value, which compounds $74.2 \%$ of the $\Pi$. On the other hand, as expected, the biogas presented the lowest $\Pi$ value, which is $73 \%, 60 \%$ and $51.2 \%$ lower than those found for bioethanol, Brazilian gasoline, and gasoline A, respectively. The $50 \%$ bioethanol $+50 \%$ biogas resulted in a $\Pi$ value $15 \%$ higher than that found for gasoline A, but it was 5.7\% lower when compared to the Brazilian gasoline. Thus, the DFSIE fuelled with 50\% bioethanol and 50\% biogas can contribute to reducing the GHG that aggravates the effects caused to human toxicity and global warming. 


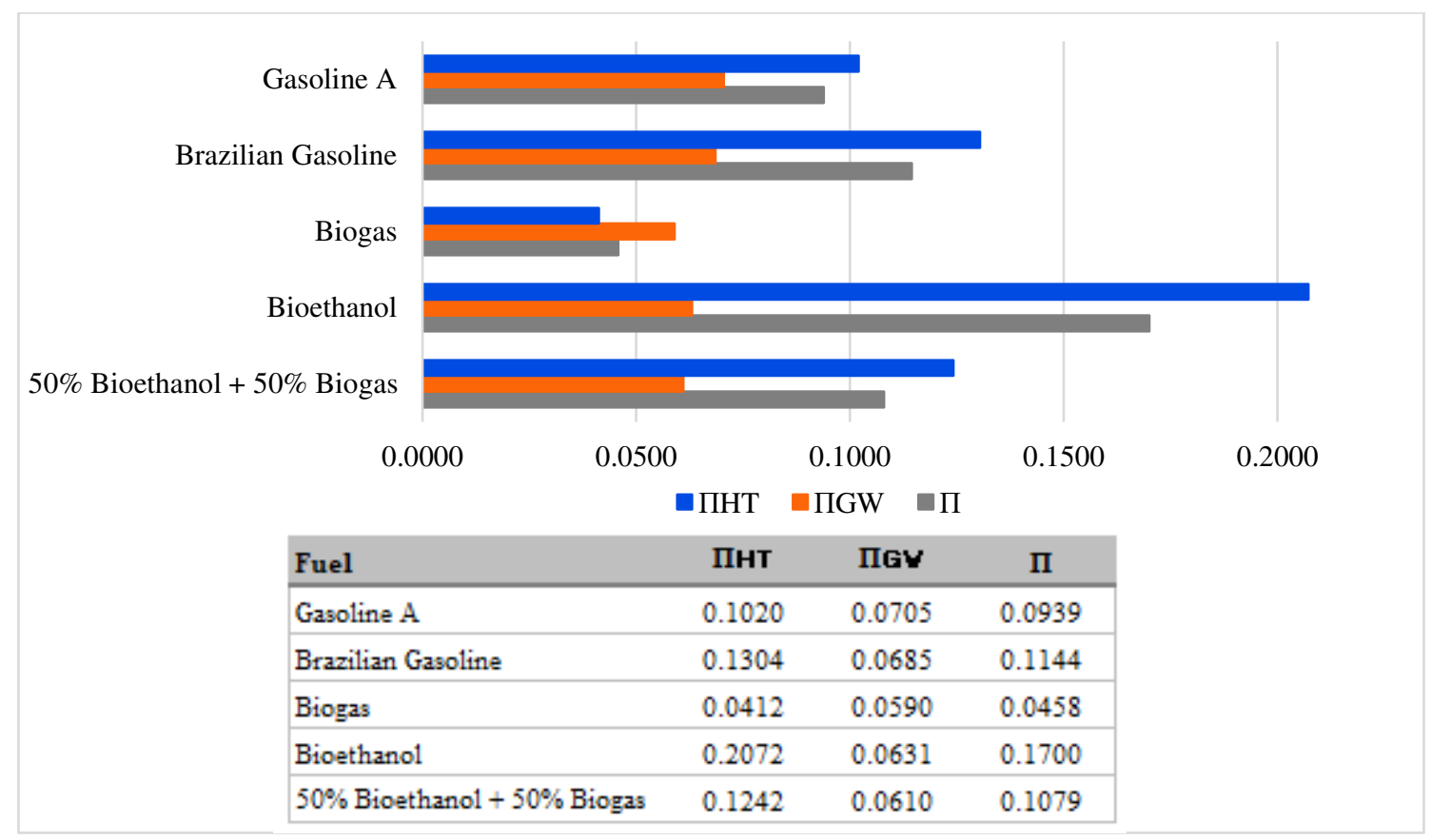

Figure 5. Human toxicity, global warming and pollution indicators found for different fuels analysed.

\subsection{Energy-ecological efficiency in the series PHEV}

The energy-ecological efficiency $(\varepsilon)$ was calculated for series PHEV through the Eq. (23) proposed by Carneiro and Gomes (2019), considering the SFSIE fuelled with gasoline A and Brazilian gasoline, and the DFSIE fuelled with 50\% bioethanol and 50\% biogas. In Brazil, the ICEV is also fuelled with ethanol, so the bioethanol was also analysed fuelling the SFSIE to comparison proposes. It is important to highlight that the biogas only was simulated to determine the $\varepsilon$ of the DFSIE, not been used as a main fuel.

First, the simulation was performed individually for each fuel-air mixture and after the percentage were applied, in case of the dual-fuel mode and the Brazilian gasoline. Fig. 8 shows the $\varepsilon$ of the SFSIE fuelled with gasoline A, Brazilian gasoline, and bioethanol, and the DFSIE fuelled with 50\% bioethanol and 50\% biogas. In the latter, the proportion of 50\% was multiplied to the bioethanol $\Pi$ and then summed to the $50 \%$ biogas $\Pi$ to determine the total $\Pi$ and the $\varepsilon$ of the DFSIE. For the Brazilian gasoline, 27\% bioethanol was mixed in the gasoline, considering a SFSIE, then the $\Pi$ and the $\varepsilon$ were determined. 


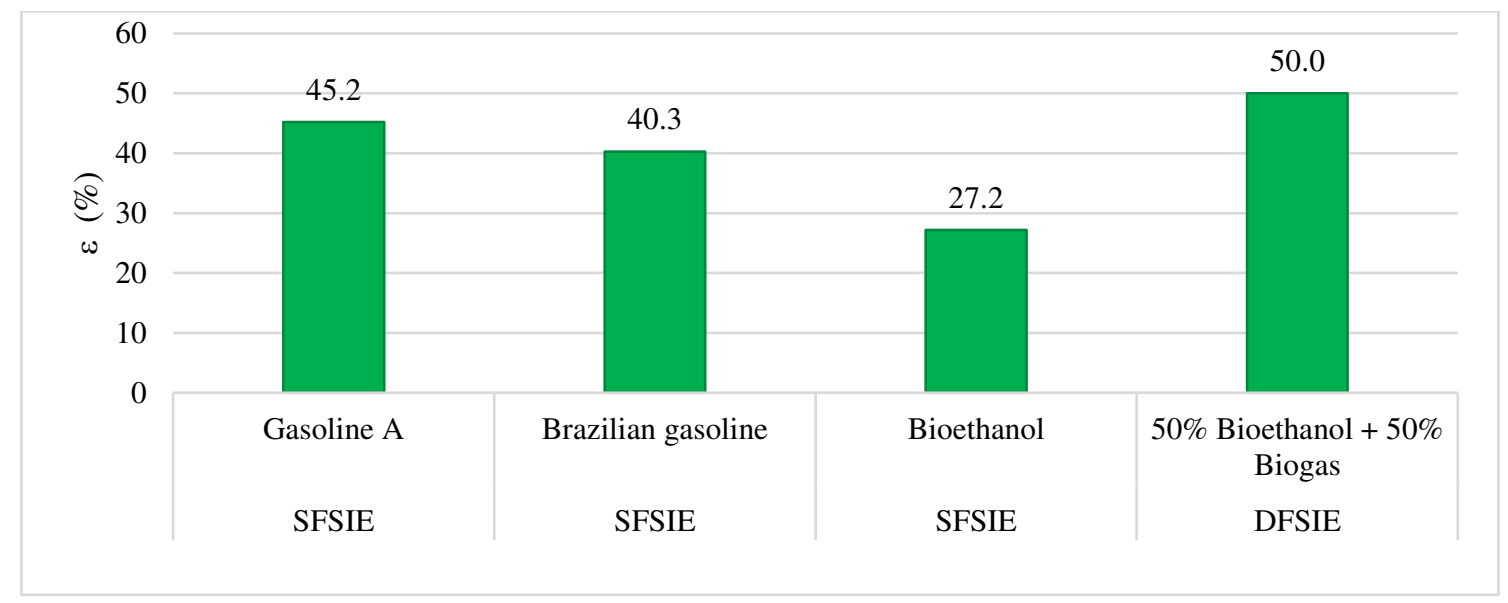

Figure 5. Energy-ecological efficiency for different fuels in SFSIE and DFSIE.

As can be seen, the highest $\varepsilon$ values were found for the DFSIE due to the lowest level of species resulting from biogas combustion, even with the high species emission factors resulting from the bioethanol combustion, that threaten human health and the environment. The DFSIE presented results $10.7 \%$ higher than the gasoline A and $24.1 \%$ higher than the Brazilian gasoline, indicating that the proposal of this study is an alternative to reduce the negatives impacts to the environmental and the human health. However, bioethanol and biogas produced from sugarcane have a percentage of atmospheric $\mathrm{CO} 2$ fixed during the growth of the plant, which is returned to the atmosphere after consumption, resulting in less negative impacts on the environment.

\subsection{WTW emissions of series PHEV}

From the analysis carried out through the GREET software, the WTP emissions from Brazilian sugarcane bioethanol and biogas production pathways were evaluated. Table 11 shows the $\mathrm{CO}_{2}, \mathrm{CH}_{4}$ and $\mathrm{N}_{2} \mathrm{O}$ emission factors of the production and transportation of sugarcane bioethanol and biogas.

Table 11. Emission factors of the production and transportation of sugarcane bioethanol and biogas.

\begin{tabular}{|c|c|c|c|}
\hline Stage & $f \mathrm{CO}_{2}\left(\mathrm{kgCO}_{2} / \mathrm{m}^{3}\right)$ & $f \mathrm{CH}_{4}\left(\mathrm{kgCH}_{4} / \mathrm{m}^{3}\right)$ & $f \mathrm{~N}_{2} \mathrm{O}\left(\mathrm{kg} \mathrm{N}_{2} \mathrm{O} / \mathrm{m}^{3}\right)$ \\
\hline Bioethanol production & $4.46 \mathrm{e}^{+3}$ & $2.03 \mathrm{e}^{0}$ & $5.84 \mathrm{e}^{-1}$ \\
\hline Bioethanol transportation & $5.00 \mathrm{e}^{+1}$ & $6.00 \mathrm{e}^{-2}$ & 0 \\
\hline Biogas production & $1.74 \mathrm{e}^{+1}$ & $2.61 \mathrm{e}^{+1}$ & $6.00 \mathrm{e}^{-9}$ \\
\hline Biogas transportation & $4.80 \mathrm{e}^{-3}$ & $7.07 \mathrm{e}^{-5}$ & $1.34 \mathrm{e}^{-7}$ \\
\hline
\end{tabular}

As previously said, the percentual of losses during the biogas production adopted is from 0 to $2 \%$. To evaluate the WTP emissions of the biogas production (Eq. 25), and the bioethanol WTP emissions (Eq. 24), the energy consumption in the ICE fuelled with gasoline A was calculated in Eq. (26), which resulted in $2.04 \mathrm{MJ} / \mathrm{km}$. In Fig. 6 is possible to analyse the biogas and bioethanol WTP emissions, and the WTP emissions when $50 \%$ bioethanol and $50 \%$ biogas are consumed. As can be seen, the percentage of losses during the biogas production process influences linearly the WTP emissions. Thus, the greater is the loss, the greater are the biogas WTP emissions, and consequently the greater are the WTP emissions of the consumption of $50 \%$ bioethanol and $50 \%$ biogas in dual-fuel mode. It was assumed that no losses occurred during the bioethanol production process, so the bioethanol WTP emissions remains the constant value of $430 \mathrm{gCO}_{2}$ eq $/ \mathrm{km}$. When $2 \%$ of biogas was lost during the production process, the biogas WTP emissions were $230 \%$ higher than the bioethanol WTP emissions. On the other hand, when the biogas production 
process presented $100 \%$ of efficiency avoiding the losses during the process, the biogas WTP emissions would be eliminated, and the bioethanol WTP emissions resulted twice greater when compared to the dualfuel mode. To match biogas WTP emissions with bioethanol WTP emissions, losses must be less than $0.6 \%$, and consequently less emissions will be achieved. Thus, the decreasing of the percentage of losses is the main way to reduce the WTP emissions during the vinasse biogas production.

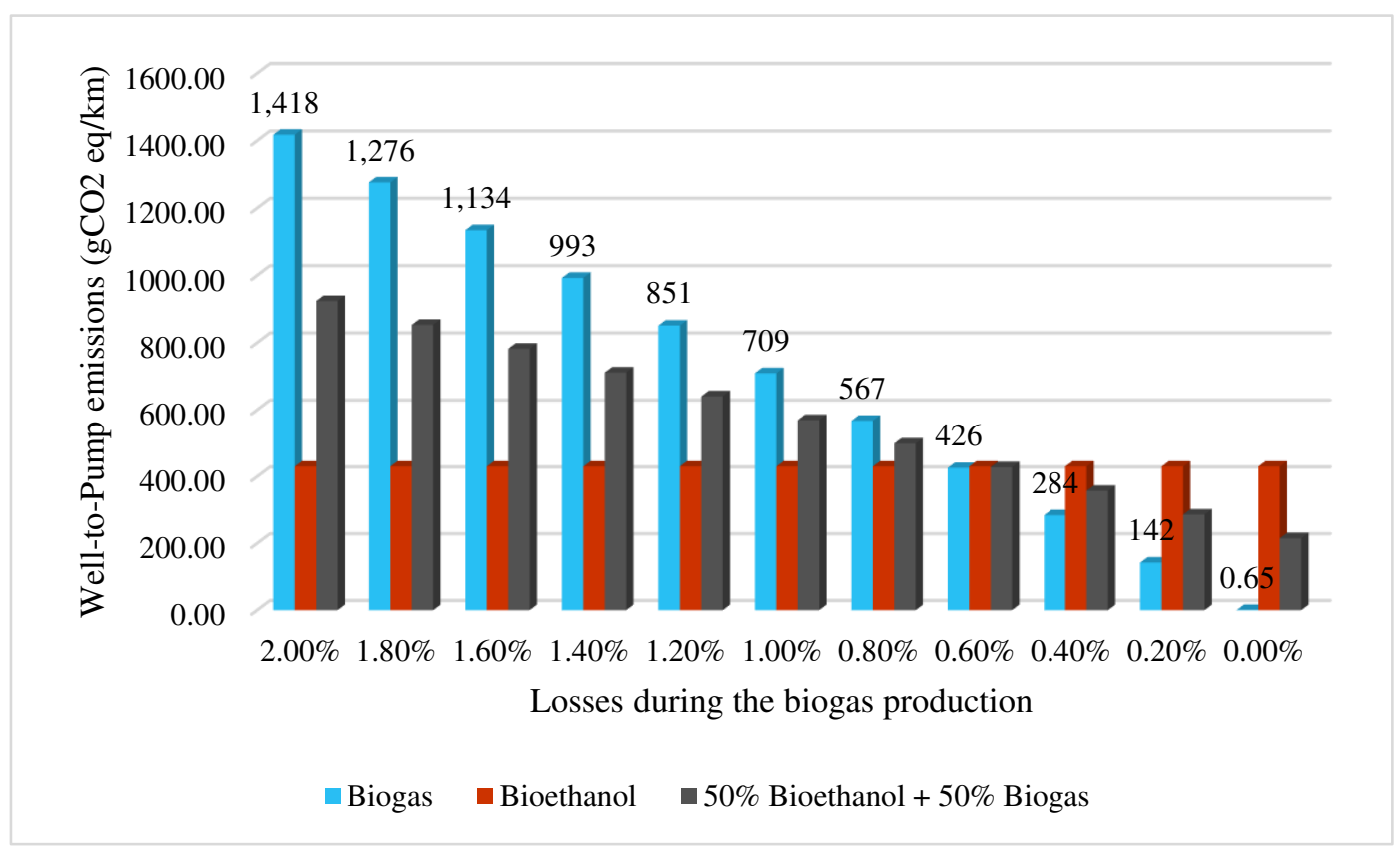

Figure 6. Well-to-Pump emissions of the biogas and bioethanol production, and of the consumption of 50\% bioethanol and $50 \%$ biogas.

Through Eq. (27), (28) and (31), the TTW emissions of the SFSIE fuelled with gasoline A, the DFSIE fuelled with $50 \%$ bioethanol and $50 \%$ biogas, and the SFSIE fuelled with Brazilian gasoline were determined. After that, the Eq. (29) was applied to determine the biogas and bioethanol consumptions, and the Eq. (30) was applied to determine the Brazilian gasoline consumption, since the gasoline A consumption was provided by the manufacturer. Table 12 shows the consumption found for each fuel and the TTW emissions are shown in Fig. 7. The biogas was analysed to illustrate the influence of its losses in the dualfuel mode emissions, so it will not appear in the TTW and WTW emissions as a main fuel. It is observed that the DFSIE fuelled with bioethanol and biogas presented $15.5 \%$ and $12.8 \%$ less TTW emissions than the SFSIE fuelled with gasoline A and Brazilian gasoline, respectively, indicating that the use of 50\% biogas is an alternative to reduce the emissions caused by the DFSIE. Also, the SFSIE fuelled with bioethanol, nowadays available in Brazilian refuelling stations, presented 3.4\% more TTW emissions than the DFSIE. It happens because of the proportion of 50\% biogas in DFSIE, which presents lower $\mathrm{CO}_{2}$ eq emission factor, influencing the TTW emission results. Comparing to the emission standards, the DFSIE presented TTW emissions 30.5\% higher than the EU emission standard by 2021, while the SFSIE fuelled with gasoline A, Brazilian gasoline and bioethanol presented values 51.6\%, $47.4 \%$ and $34.7 \%$ higher, respectively. Although the DFSIE does not meet none of the emission standards, this engine mode can be an alternative to at least reduce the tailpipe emissions. However, it is important to highlight that the DFSIE was fuelled with biofuels. Thus, this kind of fuel presents a percentage of carbon fixed through the photosynthetic reaction, which returns to the atmosphere after the plant consumption, that may be deducted 
from the TTW emissions caused by the burn of bioethanol and biogas from sugarcane, resulting in less aggressiveness to the environment and human health. But it will be a purpose of a further work.

Table 12. Fuel consumption of different fuels powering the ICE of the series PHEV.

\begin{tabular}{lc} 
Fuel & Fuel Consumption $(\mathbf{l} / \mathbf{k m})$ \\
\hline Gasoline A & 0.0630 \\
\hline Brazilian Gasoline & 0.0686 \\
\hline Bioethanol & 0.0911 \\
\hline Biogas & 94.75
\end{tabular}

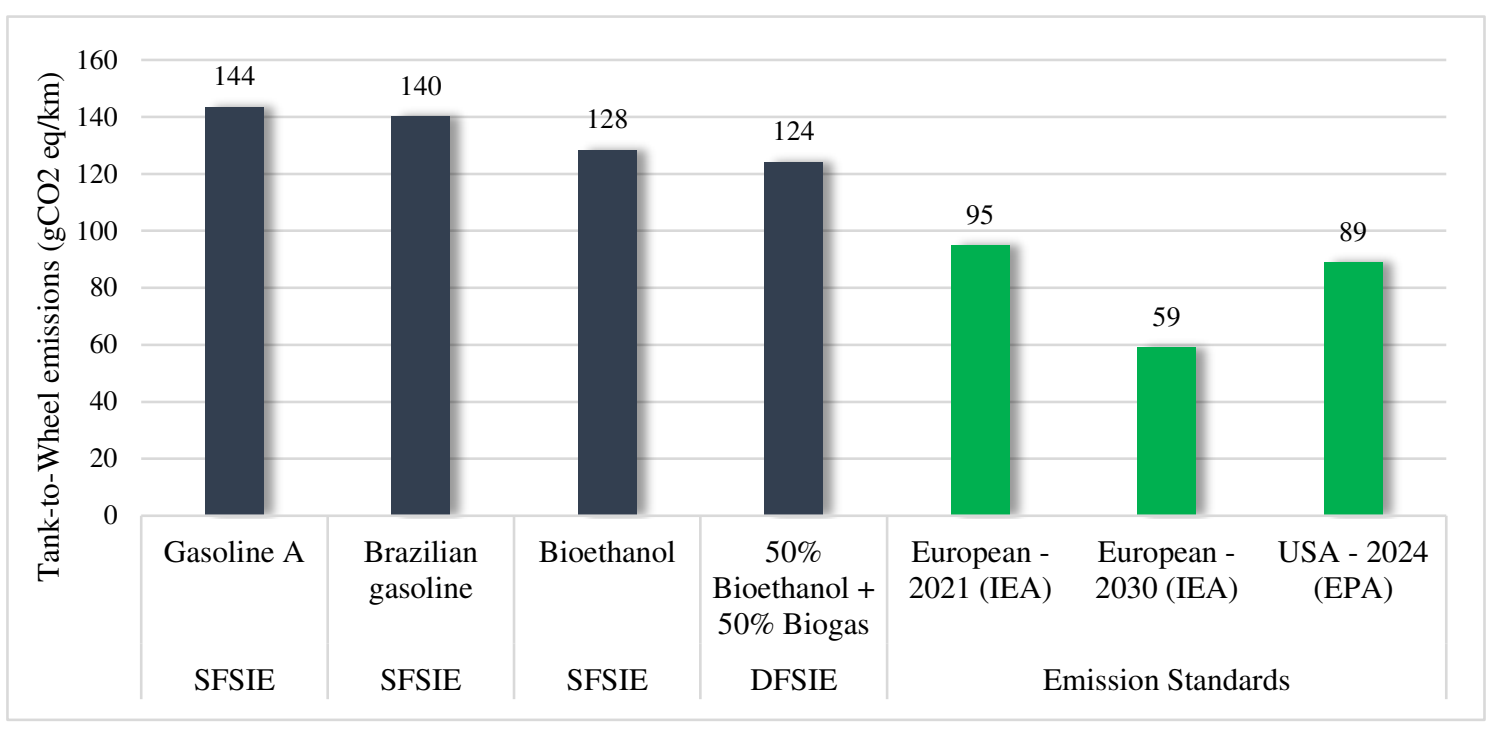

Figure 7. TTW emissions for different fuels in series PHEV.

Three electricity generation mixes using coal, natural gas, oil-fuel, and diesel oil as sources were analysed to determine the electricity mix emissions of the series PHEV Chevrolet Volt through the Eq. (32), considering its electrical energy consumption. Table 13 shows the electricity mix emissions calculated for Brazil and Spain electricity mix, and for EU provided by IRENA (2017). The Spain electricity mix presented the lowest emission value, resulting in $48.8 \%$ less emissions than the EU electricity mix. According to REE (2020), 2.2\% of the electricity in Spain was generated by fossil fuels and $4.9 \%$ by coal, in 2019, while in EU these sources were responsible for the generation of $43 \%$ of the electricity needed for the set of countries belonging to the union in 2016, according to the last version of the European Environment Agency (EEA) report. The Brazil electricity mix resulted in $12 \%$ more emissions than the EU electricity mix. However, Brazil has a mainly renewable electrical matrix, which $64.9 \%$ of the electricity generated comes from hydroelectric plants (EPE, 2020a), while the thermoelectric generation from coal and fossil fuels is responsible for only $6.4 \%$ of the national electricity generated (EPE, 2020b). Besides that, Brazil presents $83 \%$ participation of renewable sources in the electrical matrix, while the world and the OECD presented 22\% and 26\%, respectively, in 2017 (EPE, 2020a). So, if Brazil directs the electricity produced by the renewable electric matrix, it will be the least polluting among the three selected matrices.

Table 13. Electricity mix emission values for different electricity mixes.

Electricity Mix $\quad$ Eelectricity mix $\left._{\left(\mathrm{gCO}_{2} \text { eq }\right.} / \mathrm{km}\right)$




\begin{tabular}{ll}
\hline Brazil & 84.1 \\
\hline Spain & 38.4 \\
\hline European Union & 75.0
\end{tabular}

Finally, the WTW emissions of the series PHEV were analysed through the sum of the WTP, TTW and the electricity mix emissions. For comparative proposes, the biogas WTP emissions considering 0\%, $1 \%$ and $2 \%$ losses were selected to analyse the WTW emissions of the DFSIE. When the series PHEV operates in EVM, the only emissions are related to the electricity mix, as shown in Fig. 8. As can be seen, the DFSIE considering $2 \%$ losses in biogas production process is responsible for the greatest WTW emission values, $62.2 \%$ and $329 \%$ higher than those values found for $1 \%$ and $0 \%$ losses. It is due to the higher biogas WTP emission, reinforcing the need to reduce losses during the biogas production. Considering the electricity mix, the series PHEV in ERM and EVM powered by the Spain electricity mix presented the lowest WTW emissions. On the other hand, Brazil generates only $1.3 \%$ of the national electricity from fossil fuels and, when considering the sugarcane production, Brazil takes the advantages due to its rank between the biggest sugarcane producer in the world.

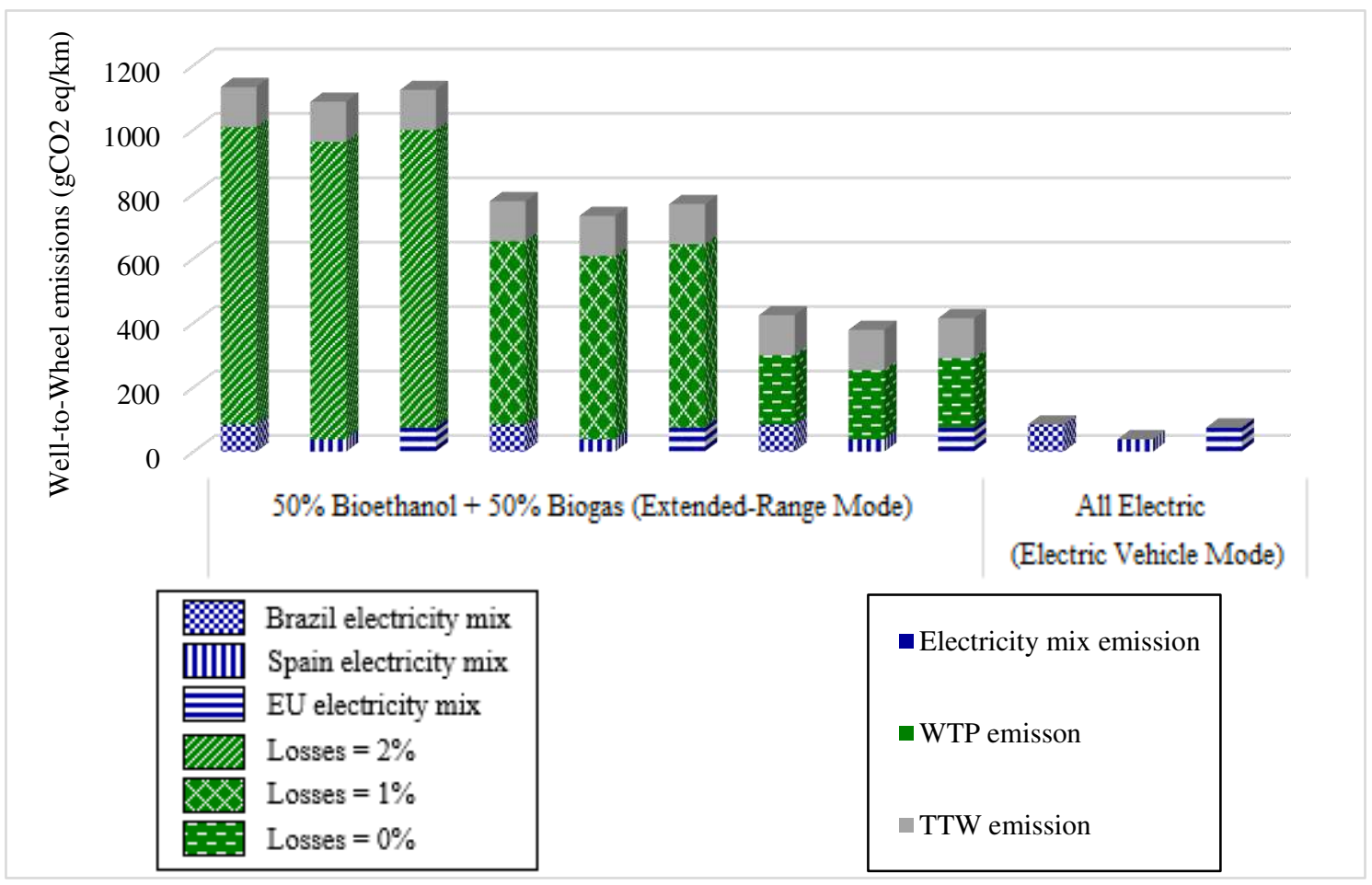

Figure 8. Well-to-wheel emissions of the sugarcane bioethanol and of the sugarcane bioethanol and vinasse biogas in dual-fuel mode.

\section{Conclusion and Further Work}

The results showed that the DFSIE fuelled with 50\% bioethanol and 50\% biogas can contribute to reducing the negative impacts to the environment. The energy-ecological efficiency of the DFSIE was $10.7 \%$ and $24.1 \%$ higher than that found for SFSIE fuelled with gasoline and Brazilian gasoline, respectively. It is due to the pollution indicator of the biogas, $73 \%, 60 \%$ and $51.2 \%$ lower than those found for bioethanol, Brazilian gasoline, and gasoline A, respectively. The percentage of losses during the vinasse biogas production aggravates linearly the WTP emissions, and consequently the WTW emissions, and is 
the main way to reduce these emissions. When $2 \%$ losses were considered, the biogas WTP emissions were $230 \%$ higher than the bioethanol WTP emissions. Otherwise, to match biogas WTP emissions with bioethanol WTP emissions, losses must be less than $0.6 \%$, and consequently less emissions will be achieved. Besides that, the DFSIE fuelled with bioethanol and biogas presented $15.5 \%$ and $12.8 \%$ less TTW emissions than the SFSIE fuelled with gasoline A and Brazilian gasoline, respectively. The DFSIE presented TTW emissions 30.5\% higher than the EU emission standard by 2021. Although the DFSIE does not meet none of the emission standards, this engine mode can be an alternative to at least reduce the tailpipe emissions. However, it is important to highlight that the DFSIE was fuelled with biofuels, which present a percentage of carbon fixed through the photosynthetic reaction, which returns to the atmosphere after the plant consumption, and may be deducted from the emissions caused by the burn of the biofuel. Among the tree electricity generation mixes analysed, the Spain electricity mix presented the lowest emissions value. The Brazil electricity mix resulted in $12 \%$ more emissions than the EU electricity mix. However, Brazil has a mainly renewable electrical matrix, while the thermoelectric generation from coal and fossil fuels were responsible for $6.4 \%$ of the national electricity generation. The comparison made in this study proved that the DFSIE fuelled with 50\% bioethanol and 50\% biogas is as alternative to replace the SFSIE fuelled with gasoline A or Brazilian gasoline, which presented higher energy-ecological efficiency, reducing the negative impacts that aggravate the human toxicity and the global warming. For further work, the carbon fixation on the sugarcane plantation will be calculated and deducted to the emissions caused by the biofuels from sugarcane.

\section{Acknowledgment}

The authors are very grateful to the financial support provided by the Iberoamerican Program of Science and Technology for Development (CYTED) with the project Smart Cities Totally Comprehensive, Efficient and Sustainable (CITIES) [518RT0557]; the Brazilian National Council for Scientific and Technological Development $(\mathrm{CNPq})$ with the project, title in Portuguese "Misturas Biogás-Biodiesel utilizadas em sistemas de injeção dual-fuel dos Motores de Combustão Interna a Compressão" [406789/2018-5] and was financed in part by the Coordenação de Aperfeiçoamento de Pessoal de Nível Superior - Brasil (CAPES) Finance Code 001. 


\section{References}

1. $\quad$ EPE (2020) Balanço energético nacional

2. Asif AA, Singh R (2017) Further cost reduction of battery manufacturing. Batteries 3:. https://doi.org/10.3390/batteries3020017

3. Singh KV, Bansal HO, Singh D (2019) A comprehensive review on hybrid electric vehicles: architectures and components. J Mod Transp 27:77-107. https://doi.org/10.1007/s40534-019-0184-3

4. Mumtaz S, Ali S, Ahmad S, et al (2017) Energy management and control of plug-in hybrid electric vehicle charging stations in a gridconnected hybrid power system. Energies 10:1-21. https://doi.org/10.3390/en10111923

5. Hu X, Martinez CM, Yang Y (2017) Charging, power management, and battery degradation mitigation in plug-in hybrid electric vehicles: A unified cost-optimal approach. Mech Syst Signal Process 87:4-16. https://doi.org/10.1016/j.ymssp.2016.03.004

6. Wang X, Liang Q (2017) Energy management strategy for plug-in hybrid electric vehicles via bidirectional vehicle-to-grid. IEEE Syst J 11:1789-1798. https://doi.org/10.1109/JSYST.2015.2391284

7. Zhang S, Xiong R, Sun F (2017) Model predictive control for power management in a plug-in hybrid electric vehicle with a hybrid energy storage system. Appl Energy 185:1654-1662. https://doi.org/10.1016/j.apenergy.2015.12.035

8. Lopez-Sanz J, Ocampo-Martinez C, Alvarez-Florez J, et al (2017) Thermal Management in Plug-In Hybrid Electric Vehicles: A Real-Time Nonlinear Model Predictive Control Implementation. IEEE Trans Veh Technol 66:7751-7760. https://doi.org/10.1109/TVT.2017.2678921

9. Cai Y, Ouyang MG, Yang F (2017) Impact of power split configurations on fuel consumption and battery degradation in plug-in hybrid electric city buses. Appl Energy 188:257-269. https://doi.org/10.1016/j.apenergy.2016.11.126

10. de Souza LLP, Lora EES, Palacio JCE, et al (2018) Comparative environmental life cycle assessment of conventional vehicles with different fuel options, plug-in hybrid and electric vehicles for a sustainable transportation system in Brazil. J Clean Prod 203:444-468. https://doi.org/10.1016/j.jclepro.2018.08.236

11. Plötz P, Funke SÁ, Jochem P (2018) The impact of daily and annual driving on fuel economy and CO2 emissions of plug-in hybrid electric vehicles. Transp Res Part A Policy Pract 118:331-340. https://doi.org/10.1016/j.tra.2018.09.018

12. Chen Y, Hu K, Zhao J, et al (2018) In-use energy and CO2 emissions impact of a plug-in hybrid and battery electric vehicle based on realworld driving. Int J Environ Sci Technol 15:1001-1008. https://doi.org/10.1007/s13762-017-1458-0

13. Niu R, Yu X, Du Y, et al (2016) Effect of hydrogen proportion on lean burn performance of a dual fuel SI engine using hydrogen directinjection. Fuel 186:792-799. https://doi.org/10.1016/j.fuel.2016.09.021

14. Chen Z, Wang L, Yuan X, et al (2019) Experimental investigation on performance and combustion characteristics of spark-ignition dualfuel engine fueled with methanol/natural gas. Appl Therm Eng 150:164-174. https://doi.org/10.1016/j.applthermaleng.2018.12.168

15. Shan X, Qian Y, Zhu L, Lu X (2016) Effects of EGR rate and hydrogen/carbon monoxide ratio on combustion and emission characteristics of biogas/diesel dual fuel combustion engine. Fuel 181:1050-1057. https://doi.org/10.1016/j.fuel.2016.04.132 Karagöz Y, Güler I, Sandalci T, et al (2016) Effect of hydrogen enrichment on combustion characteristics, emissions and performance of a diesel engine. Int J Hydrogen Energy 41:656-665. https://doi.org/10.1016/j.ijhydene.2015.09.064

17. da Costa RBR, Valle RM, Hernández JJ, et al (2020) Experimental investigation on the potential of biogas/ethanol dual-fuel spark-ignition engine for power generation: Combustion, performance and pollutant emission analysis. Appl Energy 261:114438.

https://doi.org/10.1016/j.apenergy.2019.114438 Tr CNDE (2005) Sinalização Vertical de Regulamentação. I: Leme RM, Seabra JEA (2017) Technical-economic assessment of different biogas upgrading routes from vinasse anaerobic digestion in the Brazilian bioethanol industry. Energy 119:754-766. https://doi.org/10.1016/j.energy.2016.11.029 Coronado CR, de Carvalho JA, Yoshioka JT, Silveira JL (2009) Determination of ecological efficiency in internal combustion engines: The use of biodiesel. Appl Therm Eng 29:1887-1892. https://doi.org/10.1016/j.applthermaleng.2008.10.012

21. Cârdu M, Baica M (2001) A seismic vision regarding a methodology to estimate globally the energy-ecologic efficiency of thermopower plants (TPPs). Energy Convers Manag 42:1317-1325. https://doi.org/10.1016/S0196-8904(00)00138-2 Carneiro MLNM, Gomes MSP (2019) Energy-ecologic efficiency of waste-to-energy plants. Energy Convers Manag 195:1359-1370. https://doi.org/10.1016/j.enconman.2019.05.098

23. ANP (2018) Ministério De Minas E Energia Agência Nacional Do Petróleo, Gás Natural E Biocombustíveis Presidente Da República Diretor-Geral. Agência Nac Do Petróleo, Gás Nat E Biocombustíveis 265 Afrane G, Ntiamoah A (2011) Comparative Life Cycle Assessment of Charcoal, Biogas, and Liquefied Petroleum Gas as Cooking Fuels in Ghana. J Ind Ecol 15:539-549. https://doi.org/10.1111/j.1530-9290.2011.00350.x

25. EPE (2020) Anuário Estatístico de Energia Elétrica

26. IRENA (2017) Biogas for Road Vehicles Technologu Brief

27. ANP (2019) Anuário Estatístico Brasileiro. 1-264 

Agroindustria Sucroenergética ahman S, Sabnis M, Kuusisto LM, et al (2018) Models for organics removal from vinasse from ethanol production. Clean Technol Environ Policy 20:803-812. https://doi.org/10.1007/s10098-018-1496-4 Siles JA, García-García I, Martín A, Martín MA (2011) Integrated ozonation and biomethanization treatments of vinasse derived from ethanol manufacturing. J Hazard Mater 188:247-253. https://doi.org/10.1016/j.jhazmat.2011.01.096

31. Christofoletti CA, Escher JP, Correia JE, et al (2013) Sugarcane vinasse: Environmental implications of its use. Waste Manag 33:27522761. https://doi.org/10.1016/j.wasman.2013.09.005 Parsaee M, Kiani Deh Kiani M, Karimi K (2019) A review of biogas production from sugarcane vinasse. Biomass and Bioenergy 122:117125. https://doi.org/10.1016/j.biombioe.2019.01.034 Chevrolet (2016) Chevrolet Volt 2016 II Generation. Chevrolet Product Information. X:1-21

34. Xue N, Du W, Greszler TA, et al (2014) Design of a lithium-ion battery pack for PHEV using a hybrid optimization method. Appl Energy 115:591-602. https://doi.org/10.1016/j.apenergy.2013.10.044

35. Fathabadi H (2018) Novel battery/photovoltaic hybrid power source for plug-in hybrid electric vehicles. Sol Energy 159:243-250. https://doi.org/10.1016/j.solener.2017.10.071

Balki MK, Sayin C, Canakci M (2014) The effect of different alcohol fuels on the performance, emission and combustion characteristics of a gasoline engine. Fuel 115:901-906. https://doi.org/10.1016/j.fuel.2012.09.020 


\section{Nomenclature}

\%Losses Percentage of losses during the biogas production process

1.4-DCB 1.4-Dichlorobenzene substance to calculate the human toxicity

BTE $_{\text {dual-fuel }} \quad$ Brake thermal efficiency of dual-fuel mode

c, K, n Constants (Eq. 16)

$\mathrm{C}_{2} \mathrm{H}_{5} \quad$ Ethyl radical

$\mathrm{C}_{8} \mathrm{H}_{18} \quad$ Gasoline

$\mathrm{C}_{\text {bat }} \quad$ Battery capacity, in Wh

$\mathrm{CH}_{4} \quad$ Methane

$\mathrm{CO}_{2} \quad$ Carbon dioxide

$\mathrm{CO}_{2}$ eq $\quad$ Equivalent carbon dioxide

$\varepsilon_{\text {dual-fuel }} \quad$ Energy-ecological efficiency of the dual-fuel mode

$\mathrm{E}_{\text {consump }} \quad$ Energy consumption needed by the ICE of the Chevrolet Volt, in MJ/km

$\mathrm{EE}_{\text {consump }} \quad$ Electrical energy consumption of the series PHEV Chevrolet Volt, in $\mathrm{kWh} / \mathrm{km}$

Eelectricity mix Electricity mix emissions, in $\mathrm{gCO}_{2 \mathrm{eq}} / \mathrm{km}$

$f_{1.4-\mathrm{DCB} \text { eq }}$ 1.4-Dichlorobenzene emission factor, in $\mathrm{kg} 1.4-\mathrm{DCB}_{\text {eq }} / \mathrm{kg}_{\text {fuel }}$

$\mathrm{FC}_{\text {bioethanol }} \quad$ Vehicle bioethanol consumption, in $1 / \mathrm{km}$

$\mathrm{FC}_{\text {biogas }} \quad$ Vehicle biogas consumption, in $1 / \mathrm{km}$

$\mathrm{FC}_{\mathrm{BR} \text { gasol }} \quad$ Vehicle Brazilian gasoline consumption, in $1 / \mathrm{km}$

FC $_{\text {fuel }} \quad$ Vehicle fuel consumption, in $1 / \mathrm{km}$

$\mathrm{FC}_{\text {gasoline A }} \quad$ Vehicle gasoline A consumption, in $1 / \mathrm{km}$

$f_{\mathrm{CO} 2 \text { eq }} \quad$ Equivalent carbon dioxide emission factor, in $\mathrm{kgCO}_{2}$ eq $/ \mathrm{kg}_{\text {fuel }}$

$f_{\mathrm{CO} 2 \text { eq bioethanol }}$ Equivalent carbon dioxide emission factor of the bioethanol production, in $\mathrm{kgCO} \mathrm{eq}_{2} / \mathrm{m}^{3}$ bioethanol

$f_{\mathrm{CO} 2 \text { eq fuel }} \quad$ Equivalent carbon dioxide emission factor resulted from the fuel combustion, in $\mathrm{kgCO}_{2}$ eq $/ \mathrm{kg}_{\text {fuel }}$

$f_{\mathrm{CO} 2 \text { eq trans biogas }}$ Equivalent carbon dioxide emission factor of the biogas transportation, in $\mathrm{kgCO} \mathrm{Cq}_{2} / \mathrm{m}^{3}$ biogas

$f_{\mathrm{CO} 2}$ eq prod biogas $\quad$ Equivalent carbon dioxide emission factor of the biogas production, in $\mathrm{kgCO} 2 \mathrm{eq} / \mathrm{m}^{3}$ biogas

$f_{\text {specie }} \quad$ Emission factor of each species resulting from the combustion of the mixture, in $\mathrm{kg}_{\text {specie }} / \mathrm{kg}_{\text {fuel }}$

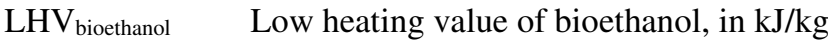




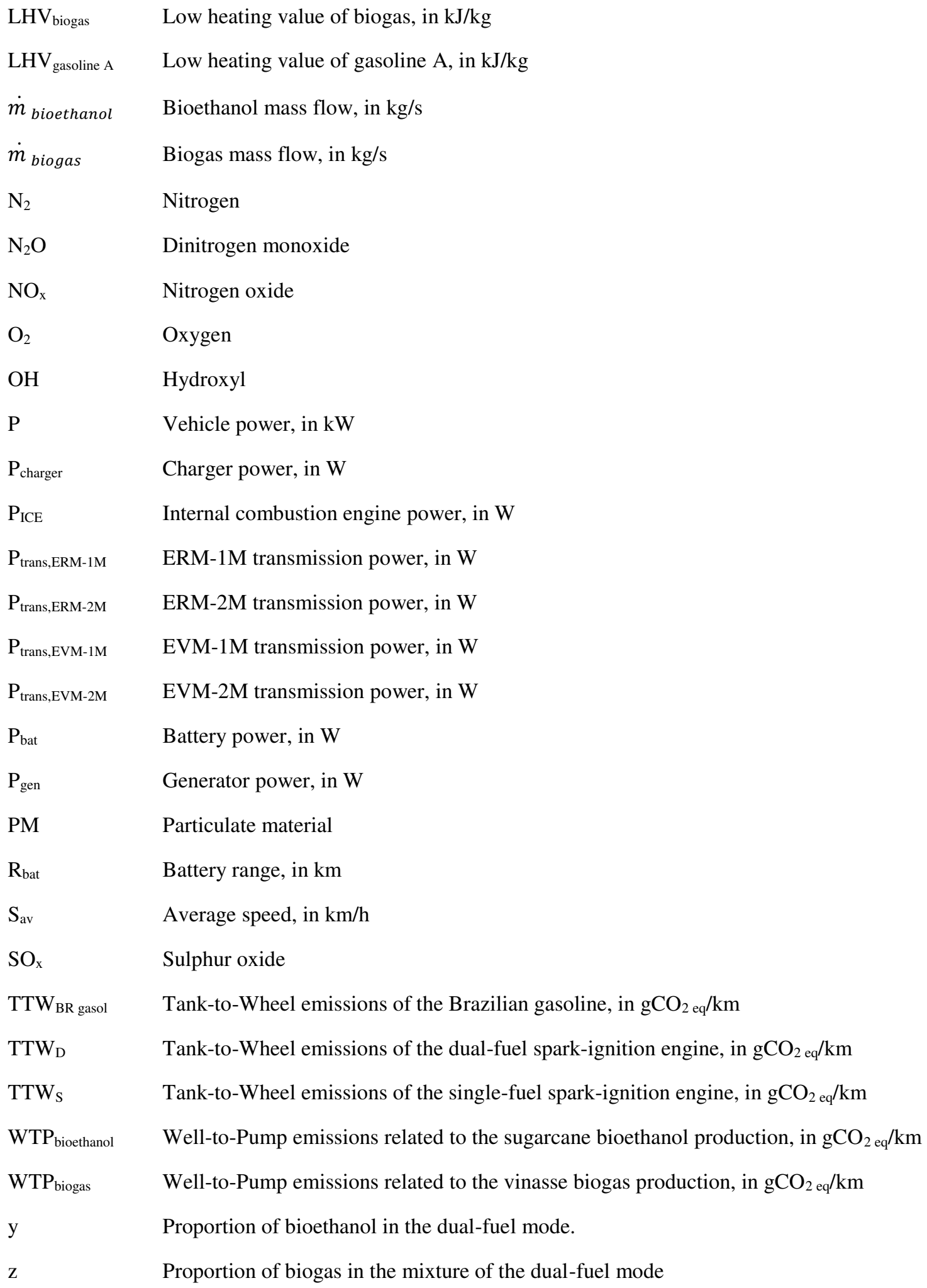


$\varepsilon$

$\eta_{\text {bat }}$

$\eta_{\text {gen }}$

$\eta_{\mathrm{EM}}$

$\eta_{\text {ERM-1M }}$

$\eta_{\text {ERM-2M }}$

$\eta_{\text {EVM-1M }}$

$\eta_{\text {EVM-2M }}$

$\eta_{\text {trans }}$

$\Pi$

$\Pi_{G W}$

$\Pi_{H T}$

$\rho_{\text {bioethanol }}$

$\rho_{\text {biogas }}$

$\rho_{\text {gasoline A }}$

$\phi$

Abbreviations

BEV

CD

CS

DFSIE

EM

ERM-1M

ERM-2M

EU

EV

EVM-1M

EVM-2M

G2V

GHG
Energy-ecological efficiency

Battery efficiency

Generator efficiency

Electric motor efficiency

ERM-1M energy efficiency

ERM-2M energy efficiency

EVM-1M energy efficiency

EVM-2M energy efficiency

Transmission efficiency

Pollution indicator, in $\mathrm{kg}_{\text {eq pollutant }} / \mathrm{MJ}_{\text {fuel }}$

Pollution indicator that contributes to global warming, in $\mathrm{kg}_{\text {eq pollutant }} / \mathrm{MJ}_{\text {fuel }}$

Pollution indicator that contributes to human toxicity, in $\mathrm{kg}_{1.4-\mathrm{DCB} \text { eq }} / \mathrm{kg}_{\text {fuel }}$

Bioethanol density, in $\mathrm{kg} / \mathrm{m}^{3}$

Biogas density, in $\mathrm{kg} / \mathrm{m}^{3}$

Gasoline A density, in $\mathrm{kg} / \mathrm{m}^{3}$

Equivalent Stoichiometry

Battery electric vehicle

Charge-depleting

Charge-sustaining

Dual-fuel spark-ignition engine

Electric motor

Extended-range mode operating with 1 motor

Extended-range mode operating with 2 motors

European Union

Electric vehicle

Electric vehicle mode operating with 1 motor

Electric vehicle mode operating with 2 motors

Grid-to-vehicle

Greenhouse gas 


$\begin{array}{ll}\text { ICE } & \text { Internal combustion engine } \\ \text { ICEV } & \text { Internal combustion engine vehicle } \\ \text { Li-ion } & \text { Lithium-ion } \\ \text { PHEV } & \text { Plug-in hybrid electric vehicle } \\ \text { SFSIE } & \text { Single-fuel spark-ignition engine } \\ \text { TTW } & \text { Tank-to-Wheel } \\ \text { USA } & \text { United States of America } \\ \text { V2G } & \text { Vehicle-to-grid } \\ \text { WTP } & \text { Well-to-Pump } \\ \text { WTW } & \text { Well-to-Wheel } \\ \text { WOT } & \text { Wide-open throttle }\end{array}$

